\title{
From emissions to ambient mixing ratios: online seasonal field measurements of volatile organic compounds over a Norway spruce-dominated forest in central Germany
}

\author{
E. Bourtsoukidis ${ }^{1,2}$, J. Williams ${ }^{1}$, J. Kesselmeier ${ }^{1}$, S. Jacobi ${ }^{3}$, and B. Bonn ${ }^{2, *}$ \\ ${ }^{1}$ Max Planck Institute for Chemistry, Mainz, Germany \\ ${ }^{2}$ Institute for Atmospheric and Environmental Sciences, J.W. Goethe University, Frankfurt/Main, Germany \\ ${ }^{3}$ Hessian Agency for the Environment and Geology, Wiesbaden, Germany \\ *now at: Sustainable Interactions With the Atmosphere, Institute for Advanced Sustainable Studies, Potsdam, Germany
}

Correspondence to: E. Bourtsoukidis (e.bourtsoukidis@mpic.de)

Received: 1 August 2013 - Published in Atmos. Chem. Phys. Discuss.: 18 November 2013

Revised: 14 May 2014 - Accepted: 23 May 2014 - Published: 1 July 2014

\begin{abstract}
Biogenic volatile organic compounds (BVOCs) are substantial contributors to atmospheric chemistry and physics and demonstrate the close relationship between biosphere and atmosphere. Their emission rates are highly sensitive to meteorological and environmental changes with concomitant impacts on atmospheric chemistry. We have investigated seasonal isoprenoid and oxygenated VOC (oxVOC) fluxes from a Norway spruce (Picea abies) tree in central Germany and explored the emission responses under various atmospheric conditions. Emission rates were quantified by using dynamic branch enclosure and proton-transfer-reaction mass spectrometry (PTR-MS) techniques. Additionally, ambient mixing ratios were derived through application of a new box model treatment on the dynamic chamber measurements. These are compared in terms of abundance and origin with the corresponding emissions. Isoprenoids dominate the BVOC emissions from Norway spruce, with monoterpenes and sesquiterpenes accounting for $50.8 \pm 7.2 \%$ and $19.8 \pm 8.1 \%$ respectively of the total emissions. Normalizing the VOC emission rates, we have observed a trend of reduction of carbon-containing emissions from April to November, with an enhancement of oxVOC. Highest emission rates were observed in June for all measured species, with the exception of sesquiterpenes, which were emitted most strongly in April. Finally, we evaluate the temperature-dependent algorithm that seems to describe the temperature-dependent emissions of methanol, acetaldehyde and monoterpenes but
\end{abstract}

only with the use of the monthly derived values for emission potential, $E_{\mathrm{s}}$, and temperature dependency, $\beta$ factor.

\section{Introduction}

While forest ecosystems are considered to be the largest $\mathrm{CO}_{2}$ sink, global vegetation redirects a significant amount of the assimilated carbon back to the atmosphere in the form of volatile organic compounds (Guenther, 2002; Kesselmeier et al., 2002). This is a substantial investment for the plant in terms of carbon and energy (Vickers et al., 2009). Emissions of biogenic volatile organic compounds (BVOCs) from vegetation are estimated to exceed the respective anthropogenic ones by 1 order of magnitude(Guenther et al., 1995) and play a vital role in biosphere-atmosphere interactions, from their impact on the oxidative capacity of the troposphere (e.g. Atkinson and Arey 2003, Lelieveld et al., 2008) to their contribution to the formation of secondary organic aerosol (e.g. Hoffmann et al., 1997; Bonn et al., 2008) and hence in the feedback on radiative properties (Pöschl et al.,2010; Paarsonen et al., 2013). In short, BVOCs are a critical link between biology, chemistry and physics.

Tree responses to environmental and meteorological changes can create both positive and negative feedbacks on VOC emissions (Arneth et al., 2010), depending on the summed effect of the various emission driving parameters, which include physiological, physicochemical and 
environmental factors. BVOCs are associated with plant growth, development and defence (Kesselmeier and Staudt, 1999; Penuelas and Staudt, 2010). They are involved in plant communication (Baldwin et al., 2006) and reproduction by attracting pollinators (Wright et al., 2005), and they are also used by plants to deal with biotic and abiotic stresses (Vickers et al., 2009; Loreto and Schnitzler, 2010). Specifically, thermal and oxidative stress can be relieved in the presence of BVOC (Loreto and Schnitzler, 2010).

Penuelas and Llusiá (2003) estimated that an increase of $2-3{ }^{\circ} \mathrm{C}$ in global average temperature will cause BVOC emissions to increase by $25-45 \%$. Average global temperature is increasing at a rate of about $0.3^{\circ} \mathrm{C}$ per decade, with predictions estimating an increase of at least $1.5^{\circ} \mathrm{C}$ (high confidence) by the end of the century (IPCC, 2013). At the same time, background ozone concentrations have more than doubled since pre-industrial times, and current models suggest that future global annual mixing ratios will reach 4284 ppb by 2100 (Vingarzan et al., 2004). Ozone is considered to be the most critical pollutant for vegetation since it is phytotoxic and can significantly reduce agricultural crop yields (Matyssek et al., 2012, and references therein); northern hemispheric vegetation in particular is regarded as highly sensitive to ozone because of the humid climate (Matyssek et al., 2007). It is generally believed that isoprenoids can protect the plant against oxidative stress during photosynthesis (Loreto at al., 2001, 2004; Vickers et al., 2009; Jardine et al., 2012). Within this context, in previously reported work, Norway spruce has been found to regulate its sesquiterpene emission rates according to ambient ozone concentrations (Bourtsoukidis et al. 2012), and Karlsson et al. (2006) provided statistical evidence of the negative effect of ozone on the stem diameter of mature trees. There is also some evidence to suggest that ozone causes even more damage to vegetation than drought-induced limitation of photosynthesis (Karnosky et al., 2003; Matyssek et al., 2006).

Most biogenic emission studies are focused on isoprenoids, which comprise a large and diverse class of naturally emitted VOCs, derived from five-carbon isoprene units assembled and modified in diverse biochemical pathways (Lichtenthaler et al., 1997). Because of their volatility and abundance, and hence their role in atmospheric chemistry, isoprene $\left(\mathrm{C}_{5} \mathrm{H}_{8}\right)$, monoterpenes (MT, $\left.\mathrm{C}_{10} \mathrm{H}_{16}\right)$ and, more recently, sesquiterpenes ( $\mathrm{SQT}, \mathrm{C}_{15} \mathrm{H}_{24}$ ) dominate BVOC emission studies. However, plants also emit a large amount of oxygenated VOCs (oxVOC) such as methanol $\left(\mathrm{CH}_{4} \mathrm{O}\right)$, acetaldehyde $\left(\mathrm{C}_{2} \mathrm{H}_{4} \mathrm{O}\right)$, ethanol $\left(\mathrm{C}_{2} \mathrm{H}_{6} \mathrm{O}\right)$ and acetone $\left(\mathrm{C}_{3} \mathrm{H}_{6} \mathrm{O}\right)$ (Kesselmeier and Staudt, 1999), the importance of which needs to be better addressed in future studies (Oderbolz et al.,2013). Short-term laboratory experiments provide valuable information under controlled conditions, but their results are not comparable with longer term field experiments (Kivimäenpää et al., 2013) due to the controlled unnatural environments they grow in. Therefore, seasonal field campaigns that cover a wide spectrum of environmental and me- teorological conditions are key for understanding emission responses and trends, along with the impact on ambient mixing ratios and atmospheric chemistry.

More realistic emission rates are obtained from a wellventilated dynamic branch enclosure where environmental parameters are close to ambient levels (e.g. Ortega and Helmig, 2008). Assuming homogenous mixing inside the chamber, when the enclosure is open, the measurements should reflect ambient mixing ratios, albeit at a point closely positioned to the emitting branch. Here, we provide a box model method that calculates ambient mixing ratios, for which the seasonality is investigated and compared with the contribution of the Norway spruce emission rates for the site of interest. The main goal of this study is to address the dominant factors determining the driving forces of VOC emissions from temperate-latitude Norway spruce over a seasonal snow-free period by using dynamic enclosure and online proton-transfer-reaction mass spectrometry (PTR-MS) techniques. Since oxVOCs are dominant contributors in the total annual BVOC emissions in Europe (Oderbolz et al., 2013) but are absent in more detailed models (McKinney et al., 2011), their emission rates have been investigated in parallel with isoprenoids and compared in terms of correlation, emission potential and temperature dependencies. Monthly diel emission patterns were investigated for both VOC class compounds, and a parameterization evaluation was performed for oxVOC along with monoterpenes. Overall, we try to approach seasonal emission rates from Norway spruce in terms of environmental responses at a site that provides a high variability of atmospheric conditions.

\section{Material and methods}

\subsection{Site description}

The measurements were conducted at Taunus Observatory $\left(50^{\circ} 13^{\prime} \mathrm{N}, 8^{\circ} 26^{\prime} \mathrm{E}\right)$, which is located at the top of Kleiner Feldberg ( $825 \mathrm{~m}$ a.s.l) in central Germany. The mountaintop ecosystem experiences a variety of meteorological and chemical conditions throughout the year due to its altitude and proximity to the heavily industrialized Rhine-Main area to the southeast and to the more rural continental background in the main wind direction (northwest). Norway spruce is the dominant species in the surrounding coniferous forest, which also includes some pine trees. A few willow, mountain ash and birch trees along with shrubs and blueberry plants make up the vegetation surrounding the measuring station. The managed forest ecosystem is between 60 and 80 years old. The dominant spruce trees reach a maximum height of about $17 \mathrm{~m}$, but the lowest living branches can also be found at $2 \mathrm{~m}$ height at the edge of the forest, where measurements took place. Further information on the forest characteristics can be found in Crowley et al. (2010) and Bonn et al. (2013). 


\subsection{Basic atmospheric measurements}

The summit of Kleiner Feldberg was cleared of trees in about a $100 \mathrm{~m}$ radius of the summit half a century ago, giving space for continuous meteorological and environmental measurements, which are conducted by the German weather service (DWD, Deutscher Wetterdienst) and the county's environmental agency (HLUG, Hessian Agency for the Environment and Geology). For the purposes of this study, a comprehensive set of meteorological and environmental data was retrieved from the aforementioned stations, with the aim of characterizing the atmospheric conditions while investigating BVOC emission responses. Temperature, global radiation, relative humidity $(\mathrm{RH})$, atmospheric pressure, wind speed and direction, sunshine duration and precipitation were the basic meteorological parameters used, while ozone $\left(\mathrm{O}_{3}\right)$, nitric oxide $(\mathrm{NO})$, nitrogen dioxide $\left(\mathrm{NO}_{2}\right)$ and atmospheric particulate matter $\left(\mathrm{PM}_{10}\right)$, in parallel with the benzene mixing ratios measured by the PTR-MS, were the main environmental parameters investigated. Additionally, a temperaturehumidity sensor (Hygrosens Instruments) and an ozone analyser (model APOA-350E, Horiba) were used to continuously monitor the temperature, relative humidity and ozone mixing ratios inside the dynamic chamber, which was used for emission rate quantification.

\subsection{Dynamic branch enclosure}

In order to obtain VOC emission rates, a dynamic branch enclosure was applied in a healthy $(13 \pm 1 \mathrm{~m}$ tall and ca. 80 years old) Norway spruce tree from 8 April to 11 November 2011, as described in Bourtsoukidis et al. (2012). Briefly, the $15 \mathrm{~L}$ cylindrical-shaped glass cuvette remained open for most of the time in order to keep the environmental parameters close to ambient levels and minimize stress to the plant (Ortega and Helmig, 2008). During the closing period, in order to avoid pressure differences, ambient air was allowed to enter the enclosure via the non-leak-tight passage of the branch at the back of the chamber (Ruuskanen et al., 2005), while an in-built fan ensured homogenous mixing. The chamber was place inside a branch $5 \mathrm{~m}$ above ground at the edge of the forest and was programmed to close for 3 min every $20 \mathrm{~min}$ as a compromise between changing conditions inside the chamber and the achievement of steady state in the VOC mixing ratios.

During May, a two-week intercomparison of temperature and relative humidity measurements indicated only small discrepancies with the ambient environment. Enclosure temperature was slightly higher than the ambient (on average $0.7^{\circ} \mathrm{C}$, $\left.R^{2}=0.97\right)$, while relative humidity was marginally lower (on average $3.1 \%, R^{2}=0.97$ ). Stronger differences were observed in a similar intercomparison with photosynthetic active radiation (PAR) during September. Two PAR sensors (LI-190SZ, LI-190SL; Li-Cor Inc., Lincoln, NB, USA) were placed inside and outside of the chamber and revealed differ- ences from 25 to $45 \%$, depending on the solar zenith angle (Bourtsoukidis et al., 2012). For the duration of the closing period, during the complete measuring period, the temperature rose on average by $0.91 \pm 0.82^{\circ} \mathrm{C}$, while relative humidity and ozone dropped by $3.5 \pm 3.5 \%$ and $2.9 \pm 2.5 \mathrm{ppbv}$ respectively. In general, the aforementioned parameters did not differ by more than $20 \%$ from open chamber conditions, apart for some rare, extreme cases $\left(\Delta \mathrm{T}_{\max }=4.3^{\circ} \mathrm{C}\right.$, $\Delta \mathrm{RH}_{\max }=39.8 \%, \Delta \mathrm{O}_{3}=21.2 \mathrm{ppbv}$ ).

\subsection{PTR-MS measurements}

Online VOC measurements were conducted by using a commercial high-sensitivity PTR-MS (Ionicon GmbH, Austria). General information about the analytical technique can be found in the literature (Lindinger et al., 1998; Blacke et al., 2009, and references therein), while more specific information about the settings of this study can be found in Bourtsoukidis et al. (2012). Briefly, the PTR-MS was operated under standard conditions with a drift tube voltage of $600 \mathrm{~V}$ and drift tube pressure of 2.3 mbar. Optimization of the instrument resulted in high and sustained primary ion signal $\left(\left[\mathrm{H}_{3} \mathrm{O}^{+}\right]=4-7 \times 10^{7} \mathrm{cps}\right)$. Frequent calibrations for the PTR-MS were performed with a gas standard containing about $1 \mathrm{ppm}$ of formaldehyde, methanol, acetaldehyde, ethanol, acetone, isoprene and $\alpha$-pinene (L4763, Ionimed Analytic GmbH, Austria), while SQTs were calibrated using a permeation oven technique and a $\beta$-caryophyllene standard (W225207, Sigma-Aldrich Inc.). Analytical fragmentation patterns were either derived experimentally or calculated according to the literature (Dhooghe et al., 2008; Kim et al., 2009; Demarcke et al., 2009). The tuning of the mass spectrometer and the transmission curve were frequently checked to achieve the best-optimized conditions. The transmission curve had minor discrepancies during the complete period and varied by less than $15 \%$, mainly in the higher masses. Since the selected branch was $5 \mathrm{~m}$ above ground and the instrumentation was kept inside a van just below the investigated tree, the sample line was very short $(4.1 \mathrm{~m})$ with a correspondingly short residence time $(2.2 \mathrm{~s})$. By choosing a chemically inert material, namely glass (inner diameter: $3 \mathrm{~mm}$ ), and by heating the inlet line up to $70^{\circ} \mathrm{C}$, the compound-specific losses were minimized and quantified prior to the measuring period in the laboratory. Similar to Kolari et al. (2012) we observed variance in the losses under different relative humidities.

The compounds continuously monitored during a PTRMS cycle (36s) along with their protonated masses were methanol $(m / z=33)$, acetaldehyde $(m / z=45)$, acetone $(m / z=59)$, isoprene $(m / z=69)$, benzene $(m / z=79)$, main MT fragment $(m / z=81)$, total MT $(m / z=137)$, nopinone $(m / z=139)$, main SQT fragment $(m / z=149)$, linalool $(m / z=155)$, pinonaldehyde $(m / z=169)$ and total SQT $(m / z=205)$. While methanol exhibits little fragmentation and the parent ion mass is considered to represent only 
this compound (Warneke et al., 2003), acetone may have interferences from propanal $(m / z=59)$. Similarly, we assume that mass 69 corresponded only to isoprene, although the dehydrated methyl butenol fragment $(m / z=69)$ has been observed to be significant in US forests (though not in European ones). Nonetheless, other isomeric aldehydes and ketones that are detected at the same mass (Fall et al., 2001; Warneke et al., 2003) add some uncertainty to the monitored mixing ratios. The masses $m / z=81$ and $m / z=137$ showed a consistent relationship throughout the year $\left(R^{2}=0.90\right)$. Hence the sum of the two signals was used to determine the total abundance of the total MT signal. The major SQT fragment $(m / z=149)$ also corresponds to methyl chavicol (BouvierBrown et al., 2009) and therefore, because of the interferences at this mass, only the parent ion signal was used, with a quantified contribution of $32 \pm 2 \%$, which is in agreement with previous studies (Kim et al., 2009).

\subsection{From emissions to ambient mixing ratios}

Emission rates of the measured VOCs were calculated by using the mass balance equation (e.g. Ruuskanen et al., 2005)

$E=F \frac{C_{2}^{\prime}-C_{1}}{m}$

here, $F$ is the total flow rate through the chamber, $C_{1}$ is the concentration at the last measurement interval before the cuvette closes and $C_{2}$ is the last measurement conducted with the closed cuvette. The final value is corrected for dilution $\left(k_{\text {dil }}\right)$, ozone reaction losses $\left(k_{\text {chem }}=k_{\mathrm{VOC} \cdot\left[\mathrm{O}_{3}\right]}\right)$ and dry deposition on the cuvette walls $\left(k_{\mathrm{dep}}\right)$ :

$C_{2}^{\prime}=C_{2} \cdot \exp \left(\left(k_{\mathrm{dil}}+k_{\mathrm{chem}}+k_{\mathrm{dep}}\right) \cdot t\right)$.

Time $t$ is the closing period ( $t=3 \mathrm{~min}$ ), while $m$ is the total dry needle biomass of the enclosed branch. The loss due to reactions with ambient ozone is not important for the oxygenated species but it does affect the highly reactive SQT emission rates, as discussed in Bourtsoukidis et al. (2012).

Hereafter, biogenic emissions were quantified in $n g g(d w)^{-1} h^{-1}$. The dry weight was determined by cutting the branch after the measurements and drying the needles for a week at $70^{\circ} \mathrm{C}$ in a temperature-controlled oven until constant weight was achieved. During the growing period, frequent length measurements were performed and the dry weight was calculated from the observed relationship between mass and length (Dittmann, 2012). All the data up to $2 \mathrm{~h}$ after the length measurements were excluded from the data analysis in order to exclude artificial, mechanically induced emissions. Since fully grown needles are heavier $\left(0.0678 \pm 0.0096 \mathrm{~g} \mathrm{~cm}^{-1}\right)$ than the newly grown $\left(0.0277 \pm 0.0023\right.$ to $0.0559 \pm 0.0061 \mathrm{~g} \mathrm{~cm}^{-1}$, depending on their development stage), fresh needles were cut from another branch and dried in order to determine their weight.
Additionally, parallel measurements of the nearby branches were also performed using the same approach. In total, Dittmann (2012) measured six different branches, i.e. two inside and four outside the enclosure, and observed an uncertainty of 16-25\%, originating from the length measurement uncertainty of $0.2 \mathrm{~cm}$ and from a slope regression of $20 \%$ and $15 \%$ for length and dry weight biomass of old and new needles, respectively. The resulting lengths of enclosed branches were split into old and new contributions and separately transferred to the estimate of dry weight biomass. Subsequently the sum was taken as the total dry weight biomass. The needle growth inside the chamber was found to be slightly larger as a result of the aforementioned slightly higher enclosure temperature. The overall uncertainty of the dry mass calculations was about $\pm 2 \mathrm{~g}$, and therefore the springtime emissions have an additional uncertainty of $10 \%$. It is important to note that all the data up to $2 \mathrm{~h}$ after the length measurements were excluded from the data analysis in order to exclude artificial, mechanically induced emissions. During DOY (day of year) 123, the enclosed branch grew substantially and in order to avoid interferences with the enclosure's lid, the back branches of the shoot were placed outside of the chamber and the new dry weight was determined in a similar way, in addition to the final cut and drying of the needles.

When the enclosure is open, it can be assumed that ambient concentrations $\left(C_{\mathrm{a}, 0}\right)$ are identical to the concentrations measured by the PTR-MS when the cuvette is open $\left(C_{1}\right)$. Here, by ambient concentrations we mean the concentrations that would have been measured at the same point but without the chamber present. Nevertheless, the measurements were conducted inside a chamber with an enclosed branch and our inlet was located on the inner side of the chamber. By using a box model when the chamber is closed, and by assuming steady state of the measured monoterpene signal, we can derive an equation that calculates the ambient concentrations:

$C_{2}=C_{\mathrm{a}, 0}+C_{\mathrm{E}}+C_{\mathrm{a}, 0} \frac{F \cdot t}{V}-C_{2} \frac{F \cdot t}{V}$,

where $V$ is the volume of the chamber and $C_{\mathrm{E}}=\frac{E \cdot m \cdot t}{V}$ is the mass entering the system as emissions. Solving the above equation for $\mathrm{Ca}$ we can derive the ambient concentrations:

$C_{\mathrm{a}, 0}=C_{2}-\frac{\frac{E \cdot m \cdot t}{V}}{1+\frac{F \cdot t}{V}}$.

Equation (4) has been evaluated by comparing the derived results with the sum of ambient monoterpene mixing ratios, as they were measured by gas chromatography-mass spectrometry (GC-MS) techniques (Nölscher et al., 2012) during the PARADE campaign (Fig. 1). The GC-MS measurements were performed $100 \mathrm{~m}$ away, and therefore further dilution effects are expected. Despite some discrepancies, averaged values for the reported period indicate a minor difference between the model and ambient mixing ratios 


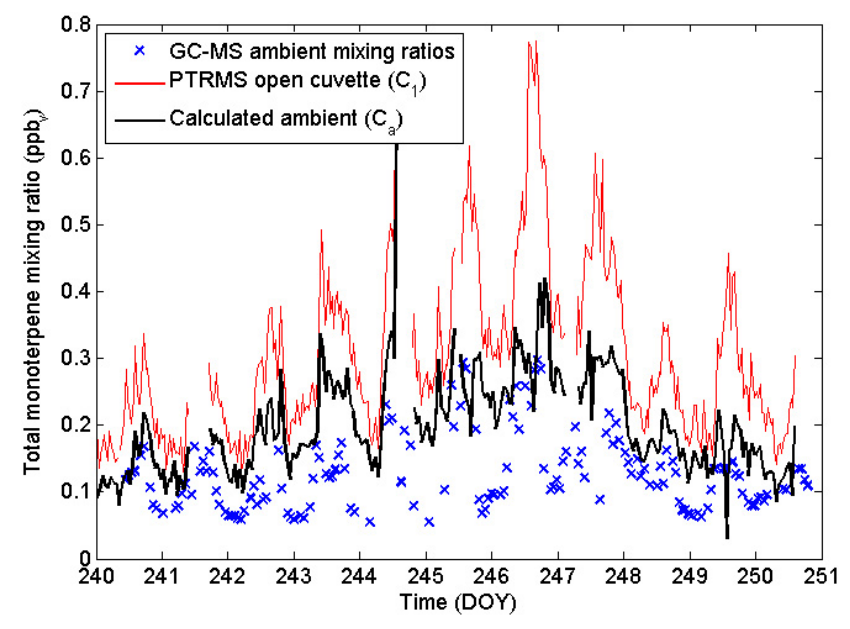

Figure 1. Comparison between the PTR-MS signal with open cuvette (red line), the GC-MS measurements conducted in the ambient atmosphere (blue crosses) and the box model calculations of Eq. (4).

$(0.056 \pm 0.021 \mathrm{ppbv})$. In contrast, raw data from the open chamber are almost double compared with ambient mixing ratios quantified by GC-MS measurements. Therefore, we assume the above equation derives representative ambient mixing ratios without the influence of the chamber, as this is supported by the comparison of these measurements. Here, we note that while Eq. (4) is in concentration, we express the difference (and the subsequent results) in ppbv for ease of comparison with other studies. Under flow-through enclosures, a second empty chamber is used as reference and ambient mixing ratios can be directly monitored. Since we have used a dynamic method and our inlet was on the inner side of the chamber and hence always affected the monitored mixing ratios, we used Eq. (4) to derive all the ambient mixing ratios presented.

\subsection{Absolute humidity}

Absolute humidity (AH) is the amount of water vapour present, expressed in $\mathrm{g} \mathrm{m}^{-3}$. Absolute humidity data indicate the leaf-to-air vapour pressure deficit (VPD), which is the driving force for transpiration and stomatal behaviour (Buck, 1981; Jones, 1992; Larcher, 1994; Franks and Farquhar, 1999). At different temperatures, different VPDs can be found, even if the relative humidity is similar. Therefore, we have used this parameter in order to link the relative humidity with the temperature. Absolute humidity was calculated by

$$
\mathrm{AH}=\mathrm{RH} \cdot \frac{6.1078 \cdot \exp \left(\frac{17.08085 \cdot T}{234.175+T}\right) \cdot M_{\mathrm{w}}}{R(273.175+T)} ;
$$

here, $T$ is the ambient temperature in ${ }^{\circ} \mathrm{C}, \mathrm{RH}$ is the relative humidity expressed in percent, $M_{\mathrm{w}}=18.016 \mathrm{~kg} \mathrm{kmol}^{-1}$ is the molecular weight of water and $R=8314 \mathrm{~J} \mathrm{k}^{-1} \mathrm{kmol}^{-1}$ is the molar gas constant.

\section{Results}

\subsection{Atmospheric conditions}

From a climatological point of view, the year 2011 can be regarded as peculiar. Spring was unusually warm and dry (precipitation anomaly $<25 \%$; DWD - comparison with 19611990 averages), with the highest annual sunshine duration since 1950 (DWD). Ozone mixing ratios were almost $20 \%$ higher, reaching an average of $55.4 \pm 14.4 \mathrm{ppbv}$, with a maximum observed value of $96.2 \pm 0.3 \mathrm{ppbv}$. In contrast, summer was relatively wet (precipitation anomaly $=126-150 \%$, DWD), with average July temperatures about $2{ }^{\circ} \mathrm{C}$ lower in comparison with the previous 14-year average. The wet summer was followed by a dry (precipitation anomaly $<50 \%$, DWD) and relatively hot autumn. Overall, the annual precipitation anomaly was -10 to $-30 \%$ (DWD). Figure 2 presents a climatological overview of temperature, global radiation, ozone and absolute humidity since 1997, along with the daily and monthly averages for the period of interest.

Northwesterly winds prevailed during most of the measuring period of spring and summer. This direction is associated with no heavily populated areas within $100 \mathrm{~km}$ and indicates a minor anthropogenic impact on the local to regional scale. In general, wind speeds were lower compared to the previous years for the period of interest $\left(\mathrm{WS}_{1997-2010}=3.83 \pm 0.5 \mathrm{~ms}^{-1}, \mathrm{WS}_{2011}\right.$ $\left.=2.96 \pm 1.4 \mathrm{~ms}^{-1}\right)$, with no major differences among the seasons $\left(\mathrm{WS}_{\text {spring }}=3.11 \pm 1.37 \mathrm{~ms}^{-1}, \mathrm{WS}_{\text {summer }}=\right.$ $2.78 \pm 1.31 \mathrm{~ms}^{-1}, \mathrm{WS}_{\text {autumn }}=3.32 \pm 1.57 \mathrm{~ms}^{-1}$ ). During autumn, the wind direction changed to south-west, originating from the heavily industrialized Rhine-Main area. This resulted in elevated $\mathrm{NO}_{\mathrm{x}}\left(\mathrm{NO}_{\mathrm{x}}=\mathrm{NO}+\mathrm{NO}_{2}\right)$ mixing ratios $\left(\mathrm{NO}_{\mathrm{x}}\right.$, spring $=3.94 \pm 2.41 \mathrm{ppbv}, \mathrm{NO}_{\mathrm{x}, \text { summer }}=$ $\left.3.52 \pm 2.32 \mathrm{ppbv}, \mathrm{NO}_{\mathrm{x}, \text { autumn }}=5.21 \pm 4.01 \mathrm{ppbv}\right)$, which were about $40 \%$ higher in comparison with both previous seasons.

\subsection{Emission rates}

Emission rates are defined as the positive fluxes calculated from Eq. (1), i.e. when the corrected maximum concentration of VOCs with closed cuvette is higher than the minimum one $\left(C_{1}\right)$ measured with open cuvette. Table 1 presents the median fluxes of all compounds measured, along with their minimum and maximum values obtained for each season.

The highest emission rates were observed for monoterpenes as a result of mechanical stress under strong winds. Such events had, however, short duration and emissions returned to normal values after several hours. It should also be noted that mechanically enhanced emissions were also induced when needle measurements necessary for the determination of the biomass dry weight were performed; however, these influences (around $2 \mathrm{~h}$ post-measurement) were easily observed and removed from the data set. Extreme emissions 

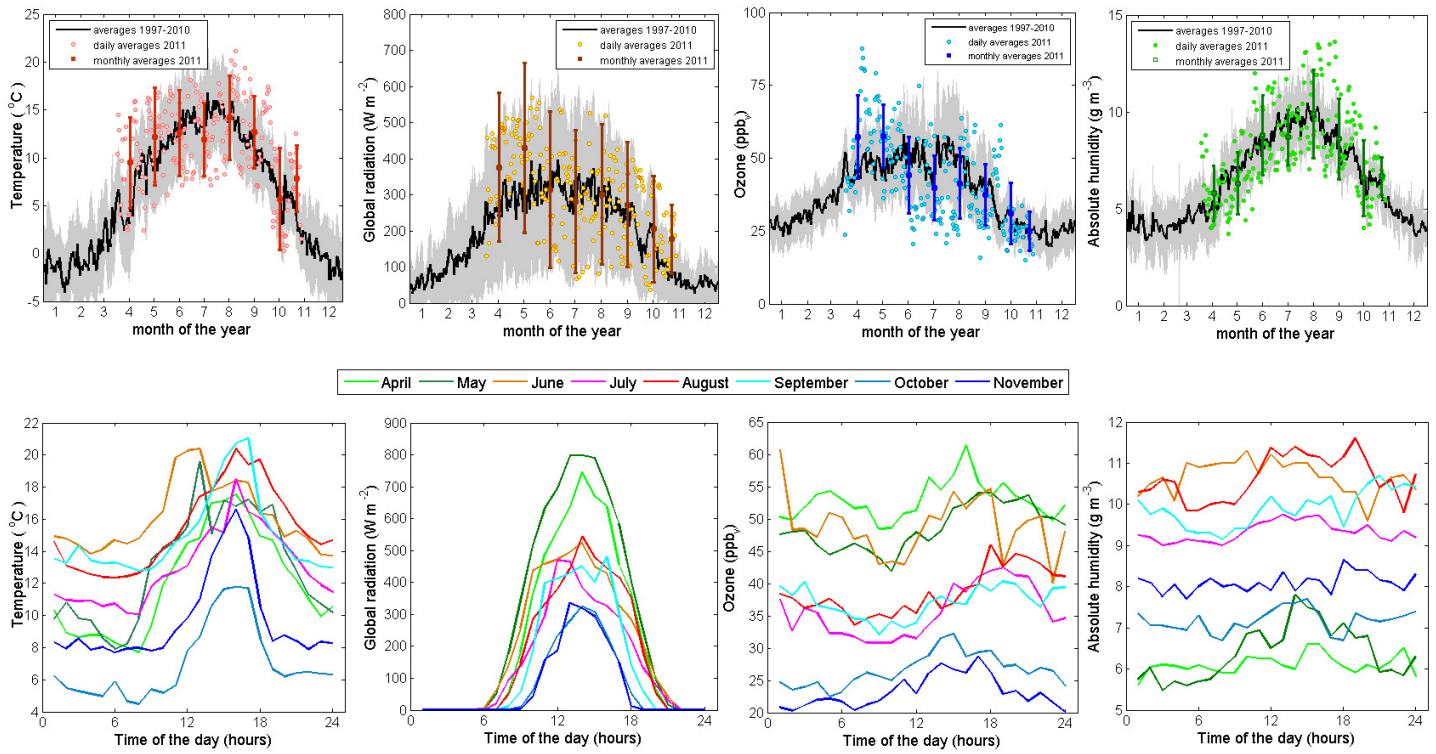

Figure 2. Top: climatological observations of temperature, global radiation, ozone and absolute humidity. The black continuous line represents the daily average from the years 1997 to 2010 and the shading their standard deviation. Daily means of the year 2011 are shown as circles, while the error bars represent the monthly means with respective standard deviations. Bottom: monthly diurnal cycles for temperature, global radiation, ozone and absolute humidity.

Table 1. Median, minimum and maximum fluxes calculated for all the compounds, measured in $\operatorname{ng} g(\mathrm{dw})^{-1} \mathrm{~h}^{-1}$. The maximum fluxes observed during summer occurred simultaneously after a storm event as a result of mechanical stress.

\begin{tabular}{lrrrrrrrrr}
\hline & \multicolumn{3}{c}{ Spring } & \multicolumn{3}{c}{ Summer } & \multicolumn{3}{c}{ Autumn } \\
\cline { 2 - 9 } & median & min & max & median & min & max & median & $\min$ & $\max$ \\
\hline Methanol & 33.7 & -5.2 & 4425.8 & 35.1 & -7.2 & 2786.2 & 20.7 & -21.8 & 152.9 \\
Acetaldehyde & 10.1 & -23.9 & 413.7 & 14.6 & -14.1 & 1422.2 & 5.3 & -19.8 & 126.4 \\
Acetone & 27.5 & -4.3 & 466.7 & 38.5 & -18.1 & 7482.2 & 16.7 & -29.3 & 322.7 \\
Isoprene & 3.7 & -11.2 & 95.5 & 3.2 & -5.8 & 128.2 & 1.6 & -5.5 & 29.3 \\
Nopinone & 0.9 & -6.4 & 98.9 & 1.2 & -8.5 & 20.3 & 0.9 & -4.7 & 6.7 \\
Linalool & 1.6 & -9.7 & 61.2 & 2.2 & -20.7 & 20.8 & 1.7 & -10.5 & 12.4 \\
Pinonaldehyde & 1.4 & -13.6 & 15.9 & 1.8 & -27.9 & 18.5 & 1.3 & -21.2 & 11.9 \\
Total MT & 203.1 & 10.9 & 8938.8 & 136.5 & 1.1 & 8434.7 & 80.8 & -1.1 & 7549.4 \\
Total SQT & 118.6 & 1.6 & 1915.4 & 64.9 & 2.4 & 878.2 & 21.4 & -0.7 & 231.9 \\
\hline
\end{tabular}

were observed during not only the growing period but also under high ambient temperatures $\left(T>30^{\circ} \mathrm{C}\right)$. Strong winds or artificial mechanical stress (i.e. length measurements) induced emissions that were up to 2 orders of magnitude stronger, compared with the ones prior to the event. Persistent and exceptionally strong emissions of methanol were observed during the growing period (May-June) as well as on some days before the new twigs started to grow, similar to the observations of Aalto et al. (2014). The strongest emission rates for the majority of ox VOC and isoprenoids occurred after a storm event in which strong winds damaged the bark of the enclosed branch (DOY 167). Interestingly, the maximum emission rates for methanol and sesquiterpenes during these wind damage events were still lower than those observed dur- ing the growing period. In order to obtain realistic emission rates representing an undamaged tree, a new branch was selected and the aforementioned data were excluded from any further analysis presented in this study.

Occasionally, negative fluxes were quantified for all compounds, but mainly for the oxygenated species. This observation can be attributed to the higher water solubility of oxVOCs, but can also be due to chemical reactions. Isoprene is highly hydrophobic and does not dissolve significantly in water. Therefore, the negative isoprene fluxes can be explained only by reactions (mainly with $\mathrm{OH}$ ) or by hypothesizing that the corresponding mass was not only assigned to isoprene but also to more soluble aldehydes and ketones that could be potentially detected in this mass. Negative 

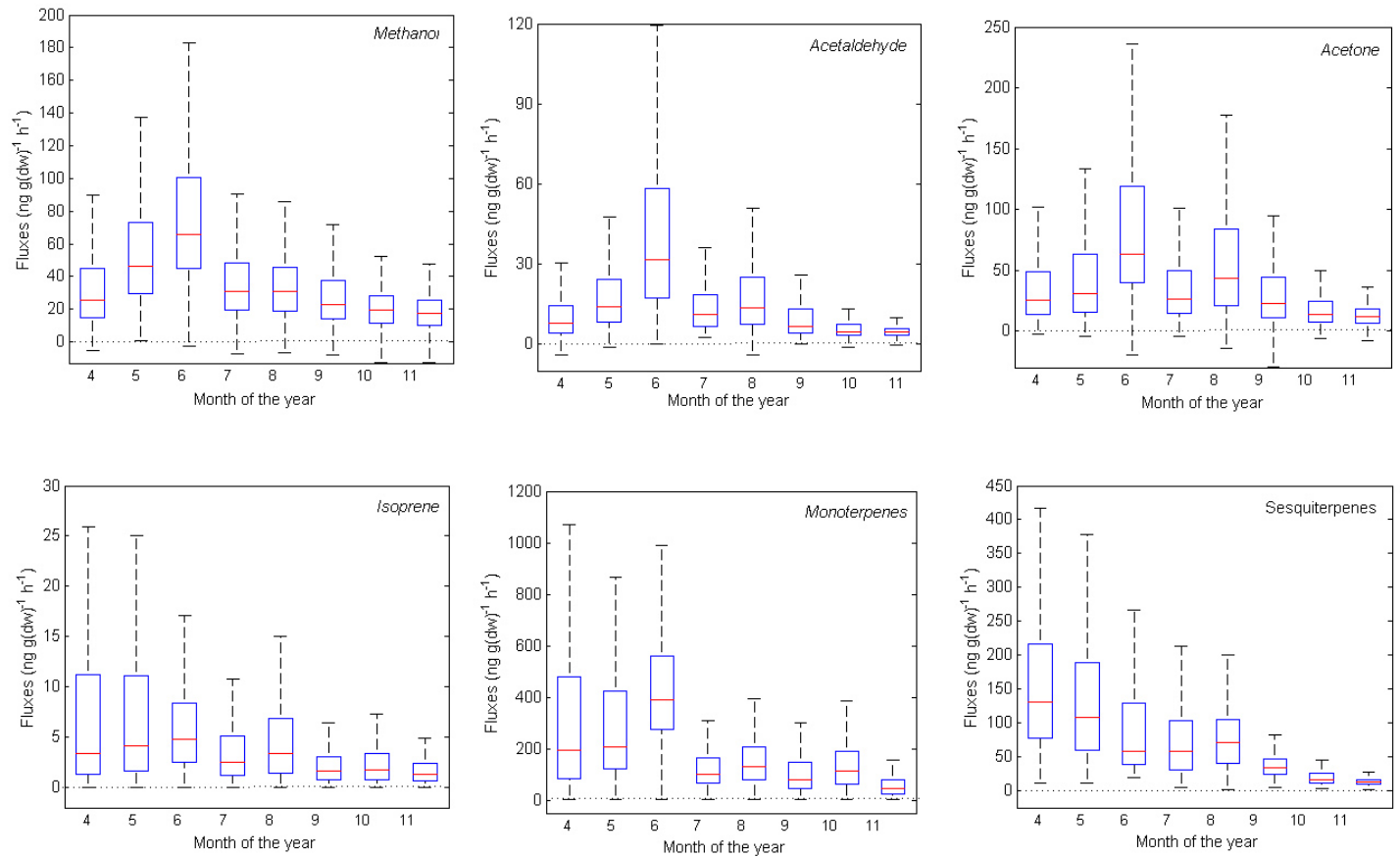

Figure 3. Box plot for the fluxes of the main oxVOC investigated (top) and for isoprenoids (bottom). On each box, the central mark is the median and the edges of the box are the 25 th and 75 th percentiles.

acetaldehyde and acetone fluxes were mainly observed during rain events, but their values were always low compared to the average emissions. In general, negative fluxes occurred only sporadically and were small compared to the average for all species $(<8.9 \%)$ apart from nopinone, linalool and pinonaldehyde, which all display positive and negative fluxes of the same magnitude.

In Fig. 3 we illustrate the monthly fluxes observed for the major oxVOC and isoprenoids. All compounds (apart from sesquiterpenes) peaked during June, declined during July and peaked again in the late summer, and then gradually declined towards the end of the year. July was relatively cold and wet, and therefore reduced emissions were expected. Methanol, acetone and isoprene median emission rates in July were less than half of their respective June rates, while acetaldehyde and monoterpenes were greatly reduced, by more than $70 \%$. In contrast, sesquiterpene median emission rates were almost identical for these two months, although the emissions did rise during August, similar to the rest of the VOCs.

By investigating the individual contribution of each measured compound to the sum of VOC emissions, we found that monoterpenes dominate Norway spruce emissions through the entire measuring period (Fig. 4). With contributions varying between 43.4 and $63.4 \%$, monoterpenes accounted for $50.8 \pm 7.2 \%$ of the total seasonal emissions by mass of carbon. The second most important emitted species was the sesquiterpenes, with larger variations in their contribution (9.3-33.4\%) and an average contribution of $19.8 \pm 8.1 \%$. Methanol and acetone emissions covered approximately

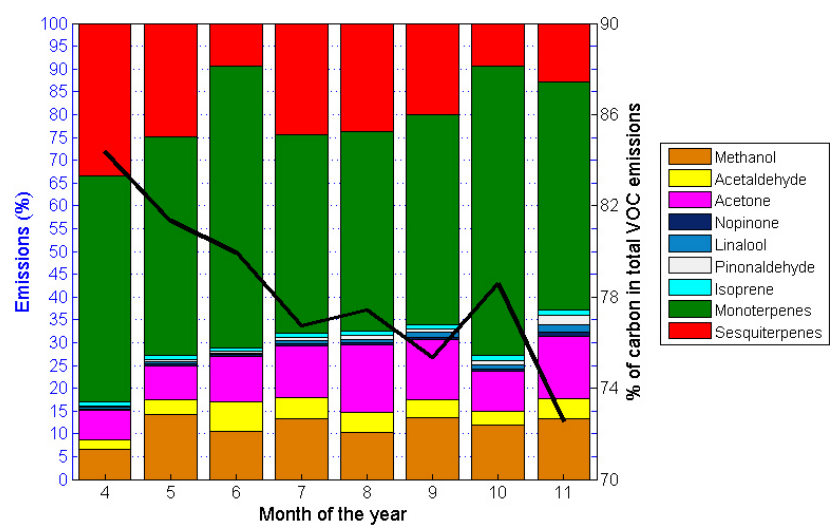

Figure 4. Normalized contribution of each VOC measured compared to the total sum of emission rates (left axis) along with the percentage of carbon in the total VOC emissions (right axis) for each month.

one-fifth of the total emissions, with similar average fractions throughout the year (methanol: $11.7 \pm 2.4 \%$; acetone: $10.7 \pm 2.8 \%$ ). Total emission rates of acetaldehyde were $4 \pm 1.3 \%$, and the remaining compounds had only a minor contribution to the total emissions: isoprene emissions constituted $1 \pm 0.16 \%$, linalool $0.8 \pm 0.4 \%$, pinonaldehyde $0.8 \pm 0.5 \%$ and nopinone $0.4 \pm 0.2 \%$.

Towards the end of the year, the oxygenated compounds' share of the total emission rates increases, and their maximum contribution $(35.9 \pm 5.4 \%)$ was observed in November 

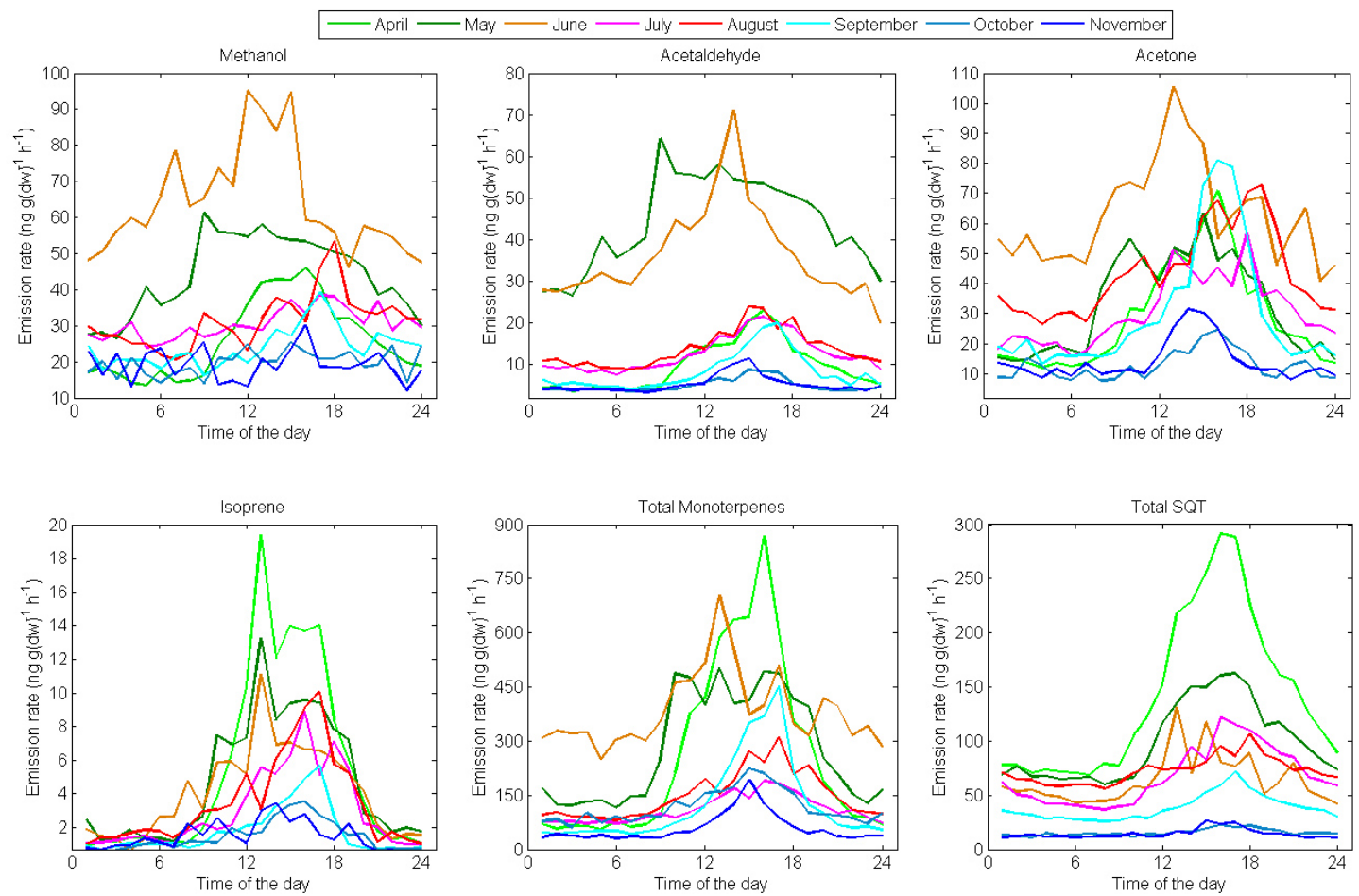

Figure 5. Diurnal patterns for the most abundant emissions from Norway spruce, including both oxVOC (top) and isoprenoids (bottom).

(Fig. 4). The average amount of carbon emitted as VOCs was calculated by season $\left(E_{\mathrm{c}, \text { spring }}=326.7 \pm 103.6 \mathrm{ng}(\mathrm{C})\right.$ $\mathrm{g}(\mathrm{dw})^{-1} \mathrm{~h}^{-1}, E_{\mathrm{c}, \text { summer }}=307.4 \pm 98.8 \mathrm{ng}(\mathrm{C}) \mathrm{g}(\mathrm{dw})^{-1} \mathrm{~h}^{-1}$, $\left.E_{\mathrm{c}, \text { autumn }}=112.2 \pm 35.9 \mathrm{ng}(\mathrm{C}) \mathrm{g}(\mathrm{dw})^{-1} \mathrm{~h}^{-1}\right)$ and the amount of carbon in the total (monitored) VOC emissions was quantified. Along with their relative contribution, in Fig. 4 we illustrate the percentage of carbon on the sum of normalized monthly emission rates. From both perspectives we can observe a tendency of reduced carbon-containing emissions and increased contribution of other species such as oxygen towards the end of the year. In general, the percentage of carbon total VOC emissions was reduced by about $10 \%$ from April to November.

Diel emissions usually peaked in the afternoon (13:0016:00), when maximum temperature and ozone occurred. However, this was not the case for all compounds and all months (Fig. 5). Methanol emissions were stronger during the growing period of May and June, with their night-time emission rates being larger than most of the daily maxima of the other months. A clear diurnal cycle was observed for methanol emissions during April, May and June but with differing temporal patterns. During May, emissions peaked after sunrise, but during June a second emission burst was observed around midday. Similar diurnal patterns were observed for acetaldehyde, with the difference being that a clear diel cycle could be observed for almost all months. Acetone emissions were characterized by a distinct diel cycle for all months and steep decline after sunset. Similar to the other oxVOC, we observe an emission burst following sunshine during May, when new twigs were growing. The diel cycle of isoprene was closely correlated with global radiation and temperature observations, and the maximum emissions occurred at local noon. Emissions during the night were within the uncertainty range of zero, but their strength during the day is closely correlated with global radiation. Monoterpene and sesquiterpene emission rates displayed a clear and distinct maximum in the afternoon during the month of April. However, May was different for both compounds, with emission bursts during early (for monoterpenes) or late (for sesquiterpenes) morning, followed by a plateau until evening. For the later months a diel cycle was always visible. Constitutive sesquiterpene emissions were also measured during October and November, with a small rise during daytime. In general, monoterpene and sesquiterpene emissions peaked with the local maxima of temperature and ozone, whereas isoprene emissions peaked at the same time with global radiation.

\subsection{Emission responses to meteorological and environmental parameters}

All measured VOC compounds clearly responded to temperature changes, with varying sensitivity among the species and the seasons. Considering the complete data set, the highest correlation coefficients $(\mathrm{CC})$ between temperature and emission rates were observed for acetone $\left(\mathrm{CC}_{T}\right.$, acetone $=$ 
$0.71 \pm 0.02)$ and monoterpenes $\left(\mathrm{CC}_{T, \mathrm{MT}}=0.63 \pm 0.03\right)$. Isoprene emissions displayed high correlation with global radiation $\left(\mathrm{CC}_{T \text {,isop }}=0.58 \pm 0.02\right)$, and an even stronger correlation was observed between sesquiterpene emissions and ambient ozone mixing ratios $\left(\mathrm{CC}_{\mathrm{O}_{3}, \mathrm{SQT}}=0.63 \pm 0.01\right)$, with a time shift of $2-4 \mathrm{~h}$ before the emissions occur. Negative correlations have been observed between all VOCs and relative humidity.

Emissions of monoterpenes and, in the absence of more detailed models, all ox VOCs are modelled by a temperaturedependent algorithm, with an exponential relationship between temperature and the induced emissions (Guenther et al., 1995):

$E=E_{\mathrm{s}, T} \cdot \exp \left(\beta \cdot\left(T-T_{\mathrm{s}}\right)\right)$.

In the above equation, $E$ is the emission rate observed at temperature $T$. Emission rates are usually expressed in $\operatorname{ng} g\left(d_{\text {textw }}\right)^{-1} \mathrm{~h}^{-1}$, where $g\left(d_{\mathrm{w}}\right)$ represents the dry weight of biomass. $E_{\mathrm{s}, T}$ is the standard emission potential at $T_{\mathrm{S}}=$ $30^{\circ} \mathrm{C}$ and $\beta$ (in $\mathrm{K}^{-1}$ ) is an empirical factor that describes the temperature dependency from the slope of the best-fit curve between the temperature and emission rates.

Emissions of sesquiterpenes are parameterized similar to monoterpenes, but with an additional term that includes the impact of ozone on induced emissions (Bourtsoukidis et al., 2012):

$E_{\mathrm{SQT}}=E_{\mathrm{S}, T} \cdot \exp \left(\beta \cdot\left(T-T_{\mathrm{S}}\right)\right)$

$+E_{\mathrm{s}, \mathrm{O}_{3}} \cdot \exp \left(\sigma \cdot\left(\left[\mathrm{O}_{3}\right]-\left[\mathrm{O}_{3, \mathrm{~s}}\right]\right)\right)$.

In the additional term, $E_{\mathrm{s}, \mathrm{O}_{3}}$ is the standard emission potential at $\left[\mathrm{O}_{3}\right]=40 \mathrm{ppbv}$ and $\sigma\left(\mathrm{in} \mathrm{ppb}_{v}^{-1}\right)$ is the respective ozone dependency.

In Table 2 we present the results of a regression analysis performed between the enclosure temperature and the emission rates, separated for different seasons and light abundance. Monoterpene emission potential was the highest calculated for every season and light abundance conditions. From a seasonal point of view, $E_{30}$ declined from spring to autumn for the majority of VOCs investigated, with the exception of acetaldehyde, which displayed the same values during spring and summer, and acetone, which had the highest emission potentials during summer.

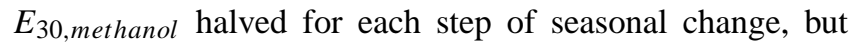
the corresponding emission potential for monoterpenes was

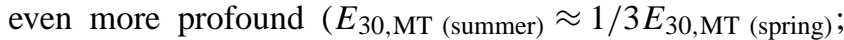

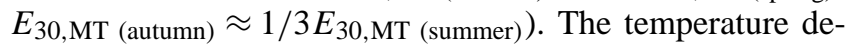
pendency was relatively constant and within the error bars for each VOC. The highest $\beta$ factor was observed for acetone and the lowest for methanol. The remaining compounds had similar annual temperature dependencies of $\beta=$ $0.11 \pm 0.02 \mathrm{~K}^{-1}$. The best fitting obtained was calculated by the regression analysis performed for sesquiterpenes during autumn. This observation demonstrates that the temperature
Table 2. Standardized emission potentials $\left(E_{30}\right.$, in $\left.\operatorname{ng} \mathrm{g}\left(d_{\mathrm{W}}\right)^{-1} \mathrm{~h}^{-1}\right)$ and temperature dependencies $\left(\beta\right.$, in $\left.\mathrm{K}^{-1}\right)$ as derived from nonlinear regression analysis (Eq. 5) for the different seasons and light conditions. $N$ is the amount of data used in the calculations and $R^{2}$ is the statistical result that expresses the quality of the fitting.

\begin{tabular}{llll}
\hline ALL $(N=16200)$ & $E_{30}$ & $\beta$ & $R^{2}$ \\
\hline Methanol & $119.8 \pm 21.9$ & $0.08 \pm 0.02$ & 0.35 \\
Acetaldehyde & $72 \pm 26.1$ & $0.11 \pm 0.04$ & 0.41 \\
Acetone & $392.7 \pm 87.1$ & $0.15 \pm 0.04$ & 0.67 \\
Total MT & $885.5 \pm 149.6$ & $0.11 \pm 0.02$ & 0.47 \\
Total SQT & $347.2 \pm 70.4$ & $0.11 \pm 0.02$ & 0.48 \\
\hline Spring $(N=4391)$ & $E_{30}$ & $\beta$ & $R^{2}$ \\
\hline Methanol & $217.2 \pm 41.7$ & $0.11 \pm 0.02$ & 0.45 \\
Acetaldehyde & $72.6 \pm 25.4$ & $0.11 \pm 0.04$ & 0.36 \\
Acetone & $325.1 \pm 57.9$ & $0.13 \pm 0.03$ & 0.62 \\
Total MT & $2837.3 \pm 368.8$ & $0.14 \pm 0.02$ & 0.58 \\
Total SQT & $533.8 \pm 61.7$ & $0.09 \pm 0.01$ & 0.41 \\
\hline Summer $(N=6625)$ & $E_{30}$ & $\beta$ & $R^{2}$ \\
\hline Methanol & $123.6 \pm 25.1$ & $0.08 \pm 0.02$ & 0.49 \\
Acetaldehyde & $70.6 \pm 22$ & $0.1 \pm 0.03$ & 0.33 \\
Acetone & $493.4 \pm 93.4$ & $0.16 \pm 0.03$ & 0.68 \\
Total MT & $977.5 \pm 140.7$ & $0.12 \pm 0.02$ & 0.45 \\
Total SQT & $352.9 \pm 56.1$ & $0.12 \pm 0.02$ & 0.43 \\
\hline Autumn $(N=5184)$ & $E_{30}$ & $\beta$ & $R^{2}$ \\
\hline Methanol & $60.9 \pm 15.7$ & $0.07 \pm 0.02$ & 0.2 \\
Acetaldehyde & $38.1 \pm 13.4$ & $0.1 \pm 0.03$ & 0.55 \\
Acetone & $247.8 \pm 70.9$ & $0.14 \pm 0.04$ & 0.62 \\
Total MT & $355.8 \pm 66.1$ & $0.08 \pm 0.01$ & 0.45 \\
Total SQT & $175.5 \pm 61.7$ & $0.11 \pm 0.01$ & 0.71 \\
\hline Day $(N=8891)$ & $E_{30}$ & $\beta$ & $R^{2}$ \\
\hline Methanol & $124.6 \pm 24.3$ & $0.09 \pm 0.02$ & 0.31 \\
Acetaldehyde & $76.5 \pm 23.3$ & $0.11 \pm 0.03$ & 0.37 \\
Acetone & $400.4 \pm 71.7$ & $0.15 \pm 0.03$ & 0.63 \\
Total MT & $1448.5 \pm 219.7$ & $0.13 \pm 0.03$ & 0.42 \\
Total SQT & $365.1 \pm 77.1$ & $0.12 \pm 0.02$ & 0.37 \\
\hline Night $(N=7309)$ & $E_{30}$ & $\beta$ & $R^{2}$ \\
\hline Methanol & $108.9 \pm 26.7$ & $0.08 \pm 0.02$ & 0.19 \\
Acetaldehyde & $52.1 \pm 21.5$ & $0.1 \pm 0.04$ & 0.27 \\
Acetone & $281.1 \pm 76.1$ & $0.15 \pm 0.04$ & 0.45 \\
Total MT & $258.6 \pm 45.7$ & $0.06 \pm 0.01$ & 0.11 \\
Total SQT & $327 \pm 57.4$ & $0.11 \pm 0.02$ & 0.32 \\
\hline & & & \\
\hline
\end{tabular}

is the main driving force of sesquiterpene emissions under low ambient $\mathrm{O}_{3}$ mixing ratios.

Methanol, acetaldehyde and sesquiterpene $E_{30}$, as well as $\beta$ factor, were unaffected by changes in light availability, as was observed by separating the data set into day and night. In contrast, monoterpene values were most affected, as their emission potential decreased by almost 6 times compared to 

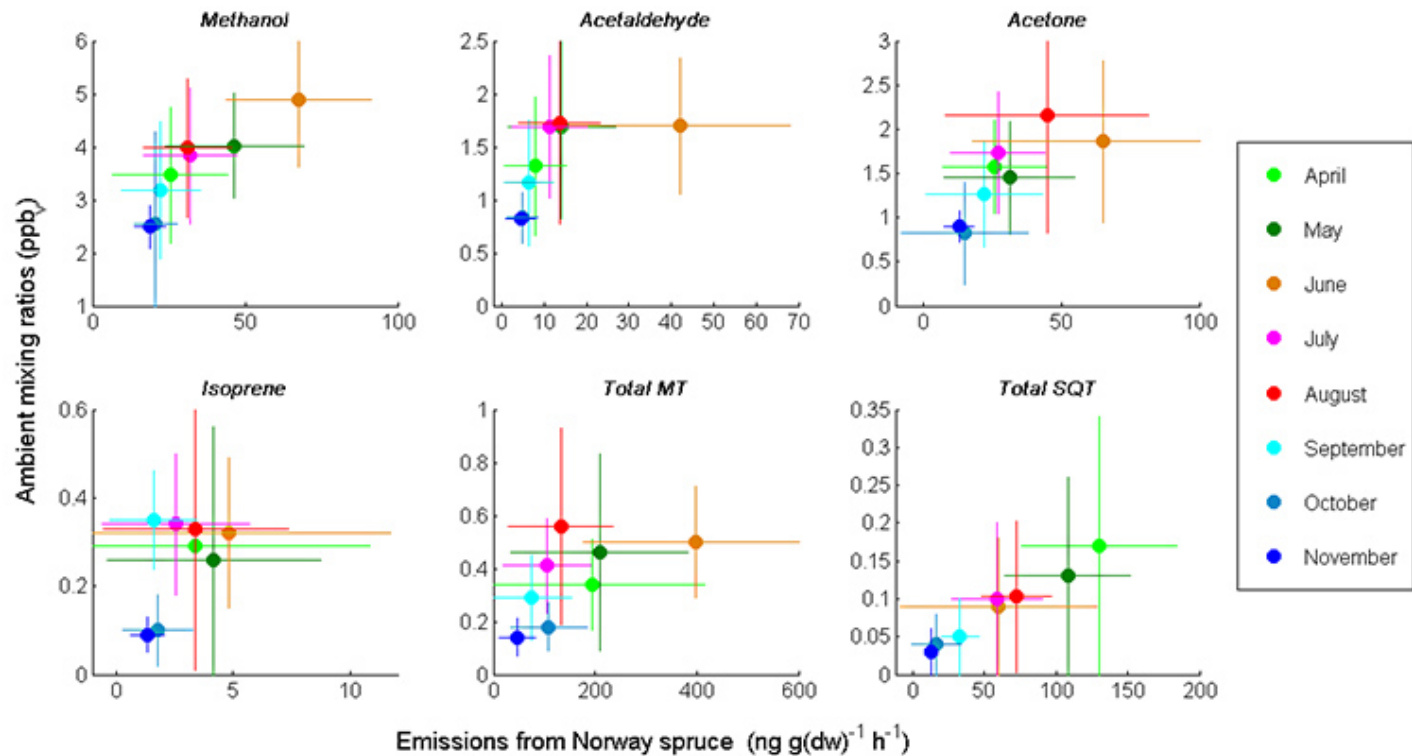

Emissions from Norway spruce (ng $\mathrm{g}(\mathrm{dw})^{-1} \mathrm{~h}^{-1}$ )

Figure 6. Monthly mean emissions from Norway spruce against the ambient mixing ratios. The linear fitting is in the form of $y=a x+b$, where $y$ is the ambient mixing ratios and $x$ the emissions. The parameters $a$ and $b$ are defined in the boxes of each plot. $R^{2}$ is the statistical result that expresses the quality of the fitting. Inside the brackets are the values obtained when considering all the data.

the daytime values. Along the same lines, temperature dependency was found to be weaker during the night $\left(\beta_{\mathrm{MT}, \text { night }}=\right.$ $\left.0.06 \pm 0.01 \mathrm{~K}^{-1}\right)$, with the lowest observed $\beta$ factor derived from the above-mentioned regression analysis. The reduced emission responses during night-time indicate that monoterpene emissions are also light-dependent, as has been noted previously in spruce emission studies (e.g. Yassaa et al. 2012).

\subsection{Ambient mixing ratios}

While isoprenoids dominate the emissions from Norway spruce, oxVOCs prevailed in terms of mixing ratio in the ambient atmosphere. As previously reported, monoterpenes accounted for $50.8 \pm 7.2 \%$ and isoprene for $1 \pm 0.16 \%$ of the total seasonal emissions. However, both species had similar abundances in the ambient mixing ratios, with monoterpenes constituting $4.7 \pm 0.8 \%$ and isoprene $3.4 \pm 0.9 \%$ of the total measured mixing ratios. This can be attributed to their different atmospheric lifetimes and atmospheric mixing. Over the measuring period, methanol was dominant in terms of mixing ratio , comprising $48.4 \pm 4.1 \%$ of the detected total ambient BVOC mixing ratios. The second most abundant compound was acetone $(20.8 \pm 1.6 \%)$, which was comparable with acetaldehyde $(19.4 \pm 1.1 \%)$. Despite the fact that sesquiterpene emissions constitute almost one-fifth of the emitted VOCs, their atmospheric contribution in terms of mixing ratio was minor $(1.1 \pm 0.5 \%)$. The dominance of oxVOC in the ambient atmosphere is due to their reduced chemical reactivity (relative to the isoprenoids), which allows them to persist over longer spatial and temporal scales (lifetimes $\tau>1$ day). In contrast, isoprenoids are highly reactive and are photochemically oxidized in a few hours or even minutes, as is the case for sesquiterpenes (Kesselmeier and Staudt, 1999). In Table 3 we present the monthly averaged mixing ratios of the VOCs measured. Highest values were measured during June, when a maximum in the Norway spruce emissions was also quantified. The highest mixing ratios for the majority of the species were observed during August, with the exception of the above-mentioned methanol and sesquiterpene mixing ratios, which followed a similar pattern to the emission rates.

Because of extremely high reactivity, which leads to short atmospheric lifetimes, sesquiterpenes cannot be transported over large distances. Additionally, there are no known anthropogenic sources of sesquiterpenes, and therefore their presence at Taunus Observatory can only be attributed to Norway spruce. This becomes clear when we plot the monthly emission rates against the ambient mixing ratios (Fig. 6). The best fitting was observed for sesquiterpenes $\left(R^{2}=0.95\right)$ and methanol $\left(R^{2}=0.80\right)$, indicating biogenic origin. Acetone and acetaldehyde display a moderate relationship between emissions and ambient mixing ratios $\left(R_{\text {acetone }}^{2}=0.63, R_{\text {acetald }}^{2}=0.71\right)$, especially when we consider the complete data set. Since Norway spruce is a weak isoprene emitter, the poor correlations observed can be attributed to deciduous trees in the vicinity. Interestingly, and despite their high emission rates, monoterpene emissions were poorly correlated with the respective mixing ratios. This may be also a result of the chemical reactions with $\mathrm{OH}$, $\mathrm{O}_{3}$ and $\mathrm{NO}_{3}$ that relatively rapidly react with the emitted monoterpenes. 
Table 3. Mean ambient mixing ratios (in ppbv) along with their standard deviations for each month.

\begin{tabular}{l|ll|lll|lll}
\hline & \multicolumn{2}{|c|}{ Spring } & \multicolumn{3}{c|}{ Summer } & \multicolumn{3}{c}{ Autumn } \\
\cline { 2 - 9 } & April & May & June & July & August & September & October & November \\
\hline Methanol & $3.47 \pm 1.28$ & $4.02 \pm 0.99$ & $4.88 \pm 1.27$ & $3.83 \pm 1.29$ & $3.98 \pm 1.31$ & $3.18 \pm 1.29$ & $2.55 \pm 1.72$ & $2.49 \pm 0.40$ \\
Acetaldehyde & $1.32 \pm 0.65$ & $1.69 \pm 0.87$ & $1.70 \pm 0.64$ & $1.69 \pm 0.67$ & $1.73 \pm 0.96$ & $1.16 \pm 0.59$ & $0.83 \pm 0.24$ & $0.82 \pm 0.11$ \\
Acetone & $1.57 \pm 0.53$ & $1.45 \pm 0.64$ & $1.86 \pm 0.92$ & $1.73 \pm 0.69$ & $2.16 \pm 1.34$ & $1.26 \pm 0.59$ & $0.82 \pm 0.58$ & $0.90 \pm 0.18$ \\
Isoprene & $0.29 \pm 0.16$ & $0.26 \pm 0.30$ & $0.32 \pm 0.17$ & $0.34 \pm 0.16$ & $0.33 \pm 0.32$ & $0.35 \pm 0.11$ & $0.10 \pm 0.08$ & $0.09 \pm 0.04$ \\
Nopinone & $0.06 \pm 0.04$ & $0.07 \pm 0.07$ & $0.11 \pm 0.07$ & $0.09 \pm 0.04$ & $0.11 \pm 0.07$ & $0.05 \pm 0.03$ & $0.03 \pm 0.02$ & $0.03 \pm 0.01$ \\
Linalool & $0.06 \pm 0.05$ & $0.06 \pm 0.06$ & $0.07 \pm 0.05$ & $0.07 \pm 0.04$ & $0.09 \pm 0.08$ & $0.04 \pm 0.03$ & $0.03 \pm 0.03$ & $0.02 \pm 0.02$ \\
Pinonaldehyde & $0.04 \pm 0.03$ & $0.03 \pm 0.03$ & $0.04 \pm 0.04$ & $0.04 \pm 0.03$ & $0.05 \pm 0.05$ & $0.02 \pm 0.02$ & $0.02 \pm 0.02$ & $0.01 \pm 0.01$ \\
Total MT & $0.34 \pm 0.17$ & $0.46 \pm 0.37$ & $0.50 \pm 0.21$ & $0.41 \pm 0.18$ & $0.56 \pm 0.37$ & $0.29 \pm 0.16$ & $0.18 \pm 0.09$ & $0.14 \pm 0.07$ \\
Total SQT & $0.17 \pm 0.11$ & $0.13 \pm 0.08$ & $0.09 \pm 0.08$ & $0.10 \pm 0.07$ & $0.10 \pm 0.06$ & $0.05 \pm 0.02$ & $0.04 \pm 0.03$ & $0.03 \pm 0.01$ \\
\hline
\end{tabular}

\section{Discussion}

In terms of climate impact, BVOCs mediate the relationship between atmosphere and biosphere (Laothawornkitkul et al., 2009), with the ability to moderate the induced climate warming by creating particles. These may subsequently act as cloud condensation nuclei and affect cloud radiative properties (Pöschl et al., 2010; Siostedt et al., 2011; Paasonen et al., 2013). Isoprenoids have been a main focus due to their highly reactive nature, but some oxVOCs may also play a substantial role (Guenther et al., 1995; Kesselmeier and Staudt, 1999; Fuentes et al., 2000) and their importance should be investigated in greater detail (Oderbolz et al., 2013). In situ emission measurements of vegetation may be the real-world indicator of the variations in the biogenic source strength of these compounds, as well as of their future ambient mixing ratios. Here, we have thoroughly examined the emission rates of isoprenoid and oxygenated VOC compounds by quantifying their emission rates along with the atmospheric abundance.

\subsection{Emission rate parameterization}

Niinemets et al. (2010) have discussed the problems with current isoprenoid emission algorithms, emphasizing the need to include missing environmental and physicochemical controls in the parameterizations. Progress has been made by establishing the Model of Emissions of Gases and Aerosols from Nature (MEGAN), which includes biological, physical and chemical driving variables in the isoprene emission modelling (Guenther et al., 2006) but still remains empirical. Additionally, Bourtsoukidis et al. (2012) recently suggested an algorithm that includes the impact of ambient ozone concentrations in the induced sesquiterpene emissions. Different parameters can be tested under controlled laboratory conditions, but it must be borne in mind that these plants have grown in an unnatural environment which does not include the biotic relationships and atmospheric variability we experience in natural ecosystems. In natural environments plants can experience multiple stress factors simultaneously. These factors can act through a common biochemical mechanism elicited by temperature, light, ozone or competition, complicating investigation of their emissions between the aforementioned parameters (Holopainen and Gershenzon, 2010; Kighati et al. 2013). Additionally, we have observed a tendency of reduced carbon-containing emissions towards the end of the year (Fig. 4), which might imply additional parameters driving the emissions. It is tempting to speculate that the investment of carbon in the form of isoprenoids is more carefully used. An example that fits this line of thought is the first half of October, which was characterized by a lack of rain for more than two weeks. During this period, monoterpene emissions were stronger and began to predominate the total VOC emissions, while stomatal conductances reduced oxVOC emissions. Nevertheless, information on the physiological state of the branch is needed in order to derive robust conclusions, and these measurements should be performed in parallel for future studies of this type.

Here, we took advantage of continuous measurements on a site experiencing variable chemical and physical conditions and explored emission relationships. We found that humidity can also affect the induced emissions despite the fact that the effect of humidity is not yet included in emission models. Additionally, oxVOCs were modelled with the same temperature-dependent algorithm described by Eq. (6) (e.g. Shade and Goldstein, 2001). In Fig. 7 we evaluate this parameterization for the main oxVOC measured along with monoterpenes. Sesquiterpenes have previously been studied in detail for the site of interest (Bourtsoukidis et al., 2012), but the lack of continuous PAR measurements does not allow for similar comparison between measurements and the temperature and light-dependent algorithm that describes isoprene emissions (Guenther et al., 1995). The results indicate that Eq. (6) can indeed describe the measured emission rates, but it is critical to include the monthly (or seasonal) emission potentials and temperature dependencies. While using the net emission potentials and temperature dependencies, derived by performing regression analysis with the complete 

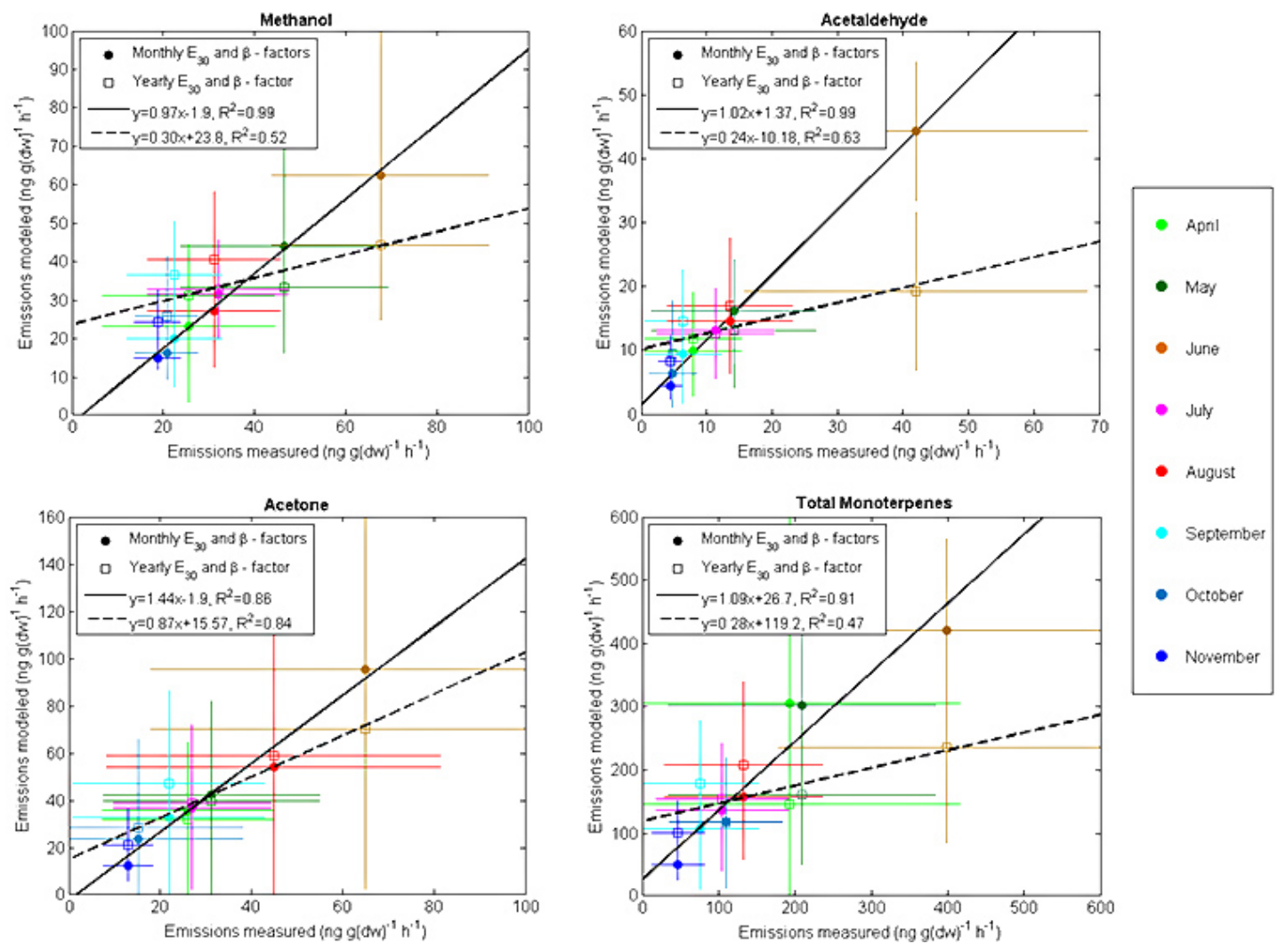

Figure 7. Comparison between measured and modelled (Eq. 6) temperature-dependent emissions for methanol, acetaldehyde, acetone and total monoterpenes. The modelled emissions that are illustrated by open squares have been calculated by using the complete data set $(N=16200)$ for the derivation of $E_{30}$ and $\beta$ factor (Table 2). The modelled emissions which are shown as filled squares have been calculated by using the respective monthly values of $E_{30}$ and $\beta$ factor. The use of monthly $E_{30}$ and $\beta$ factors substantially improve the fitting between the measurements and simulations, while the use of yearly values for these parameters strongly underestimates the measurements.

data set (Table 2), we have seen that the modelled emissions are strongly underestimated (Fig. 7).

Generally, monoterpene emissions have been found to be light-dependent not only in many European species (Staudt and Seufert, 1995; Kesselmeier et al., 1996, 1997; Ciccioli et al., 1997; Kesselmeier and Staudt, 1999; Dindorf et al., 2006) but also in tropical forests (Rinne et al., 2002; Kuhn et al., 2002; Kuhn et al., 2004; Karl et al., 2004). Our results are similar, indicating light-dependent monoterpene emissions (Table 2). In contrast, relatively few light-dependent monoterpene emissions have been observed in North America, with most of the studies indicating only temperaturedependent emissions (Schade and Goldstein, 2001; Lee et al., 2005; Helmig et al., 2006; Kim et al., 2010). The large biodiversity observed in the composition of monoterpene emissions, even among individuals of the same species (Bäck et al., 2011), may be an explanation for these diverse observations between the two continents.

\subsection{Ambient mixing ratios}

Once emitted, BVOCs enter the atmosphere, which has significant implications for atmospheric chemistry. A combination of boundary layer conditions and enhanced reactivity during the day results in lower atmospheric mixing ratios during the day and higher ones during the night (e.g. Bouvier-Brown 2009b; Hakola et al., 2012), despite the opposite pattern of emission rates. In our study, the selected tree was at the edge of the mountaintop forest, where continuous mixing takes place (Bonn et al., 2013), and as a result ambient mixing ratios were maximum during the day (Fig. 1). Independent of time, oxVOC dominated the ambient mixing ratios, as expected for European conditions (Oderbolz et al., 2013). Their impact in atmospheric reactivity is less profound than isoprenoids, but they still share an important portion of the total $\mathrm{OH}$ reactivity emission rates (Nölscher et al., 2012). Additionally their share of wintertime $\mathrm{OH}$ reactivity is enhanced as a result of reduced isoprenoid emissions (Hakola et al., 2012), and therefore their ambient mixing ratios play an important role in $\mathrm{OH}$ oxidation. Isoprenoids were less abundant in the ambient atmosphere, but despite 
their lower mixing ratios sesquiterpenes, monoterpenes and linalool dominated the organic $\mathrm{O}_{3}$ and $\mathrm{NO}_{3}$ reactivity.

\section{Conclusions}

We have obtained seasonal emission rates of the most important oxygenated VOC and isoprenoids at a site that covers a wide range of atmospheric conditions. Monoterpenes were the dominant species emitted by Norway spruce throughout the complete measuring period, accounting for almost half of the induced emissions. Especially under mechanical stress, monoterpene emission rates can increase by up to 2 orders of magnitude for several hours. Methanol and sesquiterpene emissions were also significantly enhanced under mechanical stress, but their emission rates were still low compared to the values observed during the growing period. All emission rates peaked during June and were greatly reduced during the wet and relatively cold July. Monoterpene and acetaldehyde emissions were most affected by this meteorological change, and the observed decrease in their emission rates was more than $70 \%$. Similarly, isoprene, methanol and acetone median emissions reduced by a factor of 2 during this weather transition whereas the respective sesquiterpenes did not, implying different response mechanisms. In normalized emission rates we have observed a tendency of reduced carbon-containing emissions from April to November. During this period, the portion of oxygenated species in total VOC emissions increased, but isoprenoid emissions were always dominant.

By taking advantage of the large data set obtained and the variability in atmospheric conditions, we found that emission potential and temperature dependency are highly variable under different conditions. Warm conditions raised the monoterpene temperature dependency, while the opposite was observed for sesquiterpenes. High temperatures are frequently coincident with high ozone mixing ratios, and as Bourtsoukidis et al. (2012) have shown, $\beta_{\text {SQT }}$ reached its lowest value under elevated ozone. The aforementioned fluctuation in the model parameters should be considered by the modelling community, since a universal parameter (e.g. $\beta_{\mathrm{MT}}=0.09$; Guenther et al., 1995) may substantially underestimate the temperature-dependent emissions.

In order to investigate VOC abundance in the atmosphere, we have developed a box model that derives the respective ambient mixing ratios from dynamic enclosures. In contrast with the emission rates of the dominant VOC species, oxVOC dominated the ambient mixing ratio due to their reduced reactivity and longer lifetimes relative to isoprenoids. Sesquiterpenes, methanol and acetone mixing ratios have a predominantly biogenic origin at Taunus Observatory. Isoprene may originate from other tree species (e.g. willow) since it was emitted only in negligible amounts from the Norway spruce studied.
Acknowledgements. We would like to thank W. Song (Max Planck Institute for Chemistry), H. Hakola and H. Hellén (Finnish Meteorological Institute) for the supporting GC-MS analysis. HORIBA EUROPE GmbH Semiconductor Division is thanked for performing the necessary calibrations for our ozone analyser. We are grateful to our technicians, R. Sitals and W. Haunold, for their help and fruitful discussions concerning the experimental setup, and to A. Dittmann, who performed the length measurements during the growing period. Finally, we would like to acknowledge the anonymous reviewers for their fruitful comments and suggestions, which improved the quality of the manuscript.

The service charges for this open access publication have been covered by the Max Planck Society.

Edited by: N. Mihalopoulos

\section{References}

Aalto, J., Kolari, P., Hari, P., Kerminen, V.-M., Schiestl-Aalto, P., Aaltonen, H., Levula, J., Siivola, E., Kulmala, M., and Bäck, J.: New foliage growth is a significant, unaccounted source for volatiles in boreal evergreen forests, Biogeosciences, 11, 13311344, doi:10.5194/bg-11-1331-2014, 2014.

Arneth, A., Harrison, S. P., Zaehle, S., Tsigaridis, K., Menon, S., Bartlein, P. J., Feichter, J., Korhola, A., Kulmala, M., O’Donnell, D., Schurgers, G., Sorvari, S., and Vesala, T.: Terrestrial biogeochemical feedbacks in the climate system, Nat. Geosci., 3, 525532, 2010.

Atkinson, R. and Arey, J.: Atmospheric degradation of volatile organic compounds, Chem. Rev., 103, 4605-4638, doi:10.1021/cr0206420, 2003.

Bäck, J., Aalto, J., Henriksson, M., Hakola, H., He, Q., and Boy, M.: Chemodiversity of a Scots pine stand and implications for terpene air concentrations, Biogeosciences, 9, 689-702, doi:10.5194/bg-9-689-2012, 2012.

Baldwin, I. T., Halitschke, R., Paschold, A., von Dahl, C. C., and Preston, C.: Volatile signaling in plant-plant interactions: "Talking trees" in the genomics era, Science, 311, 812-815, 2006.

Blake, R. S., Monks, P. S., and Ellis, A. M.: Proton-Transfer Reaction Mass Spectrometry, Chem. Rev., 109, 861-896, 2009.

Bonn, B., and G. K. Moortgat.: Sesquiterpene ozonolysis: Origin of atmospheric new particle formation from biogenic hydrocarbons, Geophys. Res. Lett., 30, 1585, doi:10.1029/2003GL017000, 2003.

Bonn, B., Bourtsoukidis, E., Sun, T. S., Bingemer, H., Rondo, L., Javed, U., Li, J., Axinte, R., Li, X., Brauers, T., Sonderfeld, H., Koppmann, R., Sogachev, A., Jacobi, S., and Spracklen, D. V.: The link between atmospheric radicals and newly formed particles at a spruce forest site in Germany, Atmos. Chem. Phys. Discuss., 13, 27501-27560, doi:10.5194/acpd-13-27501-2013, 2013.

Bourtsoukidis, E., Bonn, B., Dittmann, A., Hakola, H., Hellén, H., and Jacobi, S.: Ozone stress as a driving force of sesquiterpene emissions: a suggested parameterization, Biogeosciences, 9, 4337-4352, doi:10.5194/bg-9-4337-2012, 2012.

Bouvier-Brown, N. C., Goldstein, A. H., Worton, D. R., Matross, D. M., Gilman, J. B., Kuster, W. C., Welsh-Bon, D., Warneke, C., de Gouw, J. A., Cahill, T. M., and Holzinger, R.: Methyl chav- 
icol: characterization of its biogenic emission rate, abundance, and oxidation products in the atmosphere, Atmos. Chem. Phys., 9, 2061-2074, doi:10.5194/acp-9-2061-2009, 2009a.

Bouvier-Brown, N. C., Goldstein, A. H., Gilman, J. B., Kuster, W. C., and de Gouw, J. A.: In-situ ambient quantification of monoterpenes, sesquiterpenes, and related oxygenated compounds during BEARPEX 2007: implications for gas- and particle-phase chemistry, Atmos. Chem. Phys., 9, 5505-5518, doi:10.5194/acp-9-5505-2009, 2009b.

Buck, A. L.: New equations for computing vapor pressure and enhancement factor. J. Appl. Meteor., 20, 1527-1532, 1981.

Calfapietra, C., Fares, S., and Loreto, F.: Volatile organic compounds from Italian vegetation and their interaction with ozone, Environ. Pollut., 157, 1478-1486, 2009.

Ciccioli, P., Fabozzi, C., Brancaleoni, E., Cecinato, A., Frattoni, M., Loreto, F., Kesselmeier, J., Schäfer, L., Bode, K., Torres, L., and Fugit, J. L.: Use of the isoprene algorithm for predicting the monoterpene emission from the mediterranean holm oak Quercus ilex 1.: Performance and limits of this approach, J. Geophys. Res.-Atmos., 102, 23319-23328, 1997.

Cojocariu, C., Kreuzwieser, J., and Rennenberg, H.: Correlation of short-chained carbonyls emitted from Picea abies with physiological and environmental parameters, New Phytol., 162, 717727, 2004

Demarcke, M., Amelynck, C., Schoon, N., Dhooghe, F., Van Langenhove, H., and Dewulf, J.: Laboratory studies in support of the detection of sesquiterpenes by proton-transfer-reaction-mass spectrometry, Int. J. Mass Spectrom., 279, 156-162, 2009.

Dhooghe, F., Amelynck, C., Schoon, N., Debie, E., Bultinck, P., and Vanhaecke, F.: A selected ion flow tube study of the reactions of $\mathrm{H}_{3} \mathrm{O}^{+}, \mathrm{NO}^{+}$and $\mathrm{O}_{2}^{-}$with a series of sesquiterpenes, Int. J. Mass Spectrom., 272, 137-148, 2008.

Dindorf, T., Kuhn, U., Ganzeveld, L., Schebeske, G., Ciccioli, P., Holzke, C., Koble, R., Seufert, G., and Kesselmeier, J.: Significant light and temperature dependent monoterpene emissions from european beech (Fagus sylvatica l.) and their potential impact on the european volatile organic compound budget, J. Geophys. Res.-Atmos., 111, D16305, doi:10.1029/2005jd006751, 2006.

Dittmann, A.: Waldemission von Monoterpenen während der Frühjahrserholung ("spring recovery") und Frühjahrswachstums am kleinen Feldberg, Goethe University, Frankfurt, available at: http://www.uni-frankfurt.de/45685032/Bachelorarbeit_ AnnaDittmann.pdf, 2012.

Fall, R., Karl, T., Jordan A., and Lindinger, W.: Biogenic C5 VOCs: release from leaves after freeze-thaw wounding and occurrence in air at a high mountain observatory, Atmos. Environ., 35, 39053916, 2001.

Fares, S., Park, J.-H., Gentner, D. R., Weber, R., Ormeño, E., Karlik, J., and Goldstein, A. H.: Seasonal cycles of biogenic volatile organic compound fluxes and concentrations in a California citrus orchard, Atmos. Chem. Phys., 12, 9865-9880, doi:10.5194/acp-12-9865-2012, 2012.

Filella, I., Wilkinson, M. J., Llusía, J., Hewitt, C. N., and Peñuelas, J.: Volatile organic compounds emissions in Norway spruce (Picea abies) in response to temperature changes, Physiol. Plantarum, 130, 58-66, 2007.
Franks, P. J. and Farquhar, G. D.: A relationship between humidity response, growth form and photosynthetic operating point in $\mathrm{C} 3$ plants. Plant Cell Environ., 22, 1337-1349, 1999.

Fuentes, J. D., Lerdau, M., Atkinson, R., Baldocchi, D., Bottenheim, J. W., Ciccioli, P., Lamb, B., Geron, C., Gu, L., Guenther, A., Sharkey, T. D., and Stockwell, W.: Biogenic hydrocarbons in the atmospheric boundary layer: A review, B. Am. Meteorol. Soc., 81, 1537-1575, 2000.

Grabmer, W., Kreuzwieser, J., Wisthaler, A., Cojocariu, C., Graus, M., Rennenberg, H., Steigner, D., Steinbrecher, R., and Hansel, A.: VOC emissions from Norway spruce (Picea abies L. [Karst]) twigs in the field - results of a dynamic enclosure study, Atmos Environ, 40, S128-S137, 2006.

Guenther, A.: The contribution of reactive carbon emissions from vegetation to the carbon balance of terrestrial ecosystems, Chemosphere, 49, 837-844, 2002.

Guenther, A., Hewitt, C. N., Erickson, D., Fall, R., Geron, C., Graedel, T., Harley, P., Klinger, L., Lerdau, M., McKay, W. A., Pierce, T., Scholes, B., Steinbrecher, R., Tallamraju, R., Taylor, T., and Zimmerman, P.: A global model of natural volatile organic compound emissions, J. Geophys. Res., 100, 8873-8892, 1995.

Guenther, A., Karl, T., Harley, P., Wiedinmyer, C., Palmer, P. I., and Geron, C.: Estimates of global terrestrial isoprene emissions using MEGAN (Model of Emissions of Gases and Aerosols from Nature), Atmos. Chem. Phys., 6, 3181-3210, doi:10.5194/acp-63181-2006, 2006.

Helmig, D., Ortega, J., Guenther, A., Herrick, J. D., and Geron, C.: Sesquiterpene emissions from loblolly pine and their potential contribution to biogenic aerosol formation in the southeastern us, Atmos. Environ., 40, 4150-4157, 2006.

Hewitt, C. N., Ashworth, K., Boynard, A., Guenther, A., Langford, B., MacKenzie, A. R., Misztal, P. K., Nemitz, E., Owen, S. M., Possell, M., Pugh, T. A. M., Ryan, A. C., and Wild, O.: Ground-level ozone influenced by circadian control of isoprene emissions, Nature Geosci., 4, 671-674, 2011.

Hoffmann, T., Odum, J. R., Bowman, F., Collins, D., Klockow, D., Flagan, R. C., and Seinfeld, J. H.: Formation of organic aerosols from the oxidation of biogenic hydrocarbons, J. Atmos. Chem., 26, 189-222, 1997.

Holopainen, J. K. and Gershenzon, J.: Multiple stress factors and the emission of plant VOCs, Trends Plant Sci., 15, 176-184, 2010.

IPCC: Climate Change 2013: The Physical Science Basis, in: Contribution of Working Group I to the Fifth Assessment, Report of the Intergovernmental Panel on Climate Change, Cambridge University Press, 1552 pp., 2013.

Jardine, K. J., Monson, R. K., Abrell, L., Saleska, S. R., Arneth, A., Jardine, A., Ishida, F. Y., Serrano, A. M. Y., Artaxo, P., Karl, T., Fares, S., Goldstein, A., Loreto, F., and Huxman, T.: Within-plant isoprene oxidation confirmed by direct emissions of oxidation products methyl vinyl ketone and methacrolein, Glob. Change Biol., 18, 973-984, doi:10.1111/j.1365-2486.2011.02610.x, 2012.

Jones, H. G.: Plants and microclimate: a quantitative approach to environmental plant physiology, 2. Ed. Cambridge Univ. Press, 428 pp., 1992.

Karl, T., Curtis, A. J., Rosenstiel, T. N., Monson, R. K., and Fall, R.: Transient releases of acetaldehyde from tree leaves-products of a 
pyruvate overflow mechanism?, Plant, Cell Environ., 25, 1121$1131,2002$.

Karl, T., Potosnak, M., Guenther, A., Clark, D., Walker, J., Herrick, J. D., and Geron, C.: Exchange processes of volatile organic compounds above a tropical rain forest: Implications for modeling tropospheric chemistry above dense vegetation, J. Geophys. Res.-Atmos., 109, D18306, doi:10.1029/2004JD004738, 2004.

Karlsson, P. E., Örlander, G., Langvall, O., Uddling, J., Hjorth, U., Wiklander, K., Areskoug, B., Grennfelt, P.: Negative impact of ozone on the stem basal area increment of mature Norway spruce in south Sweden, Forest Ecol. Manage., 232, 146-151, 2006.

Karnosky, D. F., Zak, D., Pregnitzer, K., Awmack, C., Bockheim, J., Dickson, R., Hendrey, G., Host, G., King, J., Kopper, B., Kruger, E., Kubiske, M., Lindroth, R., Mattson, W., McDonald, E., Noormets, A., Oksanen, E., Parsons, W., Percy, K., Podila, G., Riemenschneider, D., Sharma, P., Thakur, R., Sober, A., Sober, J., Jones, W., Anttonen, S., Vapaavuori, E., Manskovska, B., Heilman, W., and Isebrands, J.: Tropospheric $\mathrm{O}_{3}$ moderates responses of temperate hardwood forests to elevated $\mathrm{CO}_{2}$ : a synthesis of molecular to ecosystem results from the Aspen FACE project. Funct. Ecol., 17, 289-304, 2003.

Kesselmeier, J. and Staudt, M.: Biogenic volatile organic compounds (VOC): An overview on emission, physiology and ecology, J. Atmos. Chem., 33, 23-88, 1999.

Kesselmeier, J., Schäfer, L., Ciccioli, P., Brancaleoni, E., Cecinato, A., Frattoni, M., Foster, P., Jacob, V., Denis, J., Fugit, J. L., Dutaur, L., and Torres, L.: Emission of monoterpenes and isoprene from a mediterranean oak species quercus ilex 1 measured within the bema (biogenic emissions in the mediterranean area) project, Atmos. Environ., 30, 1841-1850, 1996.

Kesselmeier, J., Bode, K., Hofmann, U., Müller, H., Schäfer, L., Wolf, A., Ciccioli, P., Brancaleoni, E., Cecinato, A., Frattoni, M., Foster, P., Ferrari, C., Jacob, V., Fugit, J. L., Dutaur, L., Simon, V., and Torres, L.: Emission of short chained organic acids, aldehydes and monoterpenes from quercus ilex 1 . And pinus pinea 1 . In relation to physiological activities, carbon budget and emission algorithms, Atmos. Environ., 31, 119-133, 1997.

Kesselmeier, J., Ciccioli, P., Kuhn, U., et al.: Volatile organic compound emissions in relation to plant carbon fixation and the terrestrial carbon budget, Global Biogeochem. Cy., 16, 1126, doi:10.1029/2001GB001813, 2002.

Kigathi, R. N., Weisser, W. W., Veit, D., Gershenzon, J., and Unsicker, S. B.: Plants suppress their emission of volatiles when growing with conspecifics, J. Chem Ecol, 39, 537-545, 2013.

Kim, S., Karl, T., Helmig, D., Daly, R., Rasmussen, R., and Guenther, A.: Measurement of atmospheric sesquiterpenes by proton transfer reaction-mass spectrometry (PTR-MS), Atmos. Meas. Tech., 2, 99-112, doi:10.5194/amt-2-99-2009, 2009.

Kim, S., Karl, T., Guenther, A., Tyndall, G., Orlando, J., Harley, P., Rasmussen, R., and Apel, E.: Emissions and ambient distributions of Biogenic Volatile Organic Compounds (BVOC) in a ponderosa pine ecosystem: interpretation of PTR-MS mass spectra, Atmos. Chem. Phys., 10, 1759-1771, doi:10.5194/acp-101759-2010, 2010.

Kivimäenpää, M., Riikonen, J.,Ahonen, V., Tervahauta, A., and Holopainen, T.: Sensitivity of Norway spruce physiology and terpenoid emission dynamics to elevated ozone, Environ. Experim. Bot., 90, 32-42, 2013
Kuhn, U., Rottenberger, S., Biesenthal, T., Wolf, A., Schebeske, G., Ciccioli, P., Brancaleoni, E., Frattoni, M., Tavares, T. M., and Kesselmeier, J.: Isoprene and Monoterpene emissions of Amazonian tree species during the wet season: direct and indirect investigations on controlling environmental functions. J. Geophys. Res. 107, 8071, doi:10.1029/2001JD000978, 2002.

Kuhn, U., Rottenberger, S., Biesenthal, T., Wolf, A., Schebeske, G., Ciccioli, P., Brancaleoni, E., Frattoni, M., Tavares, T. M., and Kesselmeier, J.: Seasonal differences in isoprene and lightdependent monoterpene emission by Amazonian tree species. Global Change Biology Global Change Biology 10, 663-682, doi:10.1111/j.1529-8817.2003.00771.x, 2004.

Laothawornkitkul, J., Taylor, J. E., Paul, N. D., and Hewitt, C. N.: Biogenic volatile organic compounds in the earth system, New Phytol., 183, 27-51, 2009.

Larcher, W.: Ökophysiologie der Pflanzen, 5. Auflage, Eugen Ulmer Verlag, Stuttgart, 1994.

Lee, A., Schade, G. W., Holzinger, R., and Goldstein, A. H.: A comparison of new measurements of total monoterpene flux with improved measurements of speciated monoterpene flux, Atmos. Chem. Phys., 5, 505-513, doi:10.5194/acp-5-505-2005, 2005.

Lelieveld, J., Butler, T. M., Crowley, J. N., Dillon, T. J., Fischer, H., Ganzeveld, L., Harder, H., Lawrence, M. G., Martinez, M., Taraborrelli, D., and Williams, J.: Atmospheric oxidation capacity sustained by a tropical forest, Nature Chem., 452, 737-740, 2008.

Lerdau, M.: A positive feedback with negative consiquences, Science, 316, 212-213, 2007.

Lichtenthaler, H. K., Rohmer, M., and Schwender, J.: Two independent biochemical pathways for isopentenyl diphosphate and isoprenoid biosynthesis in higher plants, Physiol. Plantarum, 101, 643-652, 1997.

Lindinger, W., Hansel, A., and Jordan, A.: On-line monitoring of volatile organic compounds at pptv levels by means of ProtonTransfer-Reaction Mass Spectrometry (PTR-MS): medical applications, food control and environmental research, Int. J. Mass Spectrom., 173, 191-241, doi:10.1016/S0168-1176(97)00281-4, 1998.

Loreto, F. and Schnitzler, J.-P.: Abiotic stresses and induced BVOCs, Trends Plant Sci., 15, 154-166, 2010.

Loreto, F., Mannozzi, M., Maris, C., Nascetti, P., Ferranti, F. and Pasqualini, S.: Ozone quenching properties of isoprene and its antioxidant role in leaves, Plant Physiol. 126, 993-1000, 2001.

Loreto, F., Pinelli, P., Manes, F., and Kollist, H.: Impact of ozone on monoterpene emissions and evidences for an isoprene-like antioxidant action of monoterpenes emitted by Quercus ilex (L.) leaves, Tree Physiol., 24, 361-367, 2004.

Matyssek, R., Le Thiec, D., Löw, M., Dizengremel, P., Nunn, A. J., and Häberle, K. H.: Interaction between drought stress and $\mathrm{O}_{3}$ stress in forest trees, Plant Biol., 8, 11-17, 2006.

Matyssek, R., Bytnerowicz, A., Karlsson, P.-E., Paoletti, E., Sanz, M., Schaub, M., and Wieser, G.: Promoting the $\mathrm{O}_{3}$ flux concept for European forest trees, Environ. Pollut., 146, 587-607, 2007.

Matyssek, R., Wieser, G., Calfapietra, C., de Vries, W., Dizengremel, P., Ernst, D., Jolivet, Y., Mikkelsen, T. N., Mohren, G. M. J., Le Thiec, D., Tuovinen, J. P., Weatherall, A., and Paoletti, E.: Forests under climate change and air pollution: gaps in understanding and future directions for research, Environ. Pollut., 160, 57-65, 2012. 
McKinney, K. A., Lee, B. H., Vasta, A., Pho, T. V., and Munger, J. W.: Emissions of isoprenoids and oxygenated biogenic volatile organic compounds from a New England mixed forest, Atmos. Chem. Phys., 11, 4807-4831, doi:10.5194/acp-11-4807-2011, 2011

Niinemets, Ü., Arneth, A., Kuhn, U., Monson, R. K., Peñuelas, J., and Staudt, M.: The emission factor of volatile isoprenoids: stress, acclimation, and developmental responses, Biogeosciences, 7, 2203-2223, doi:10.5194/bg-7-2203-2010, 2010.

Nölscher, A. C., Bourtsoukidis, E., Bonn, B., Kesselmeier, J., Lelieveld, J., and Williams, J.: Seasonal measurements of total $\mathrm{OH}$ reactivity emission rates from Norway spruce in 2011, Biogeosciences, 10, 4241-4257, doi:10.5194/bg-10-4241-2013, 2013.

Oderbolz, D. C., Aksoyoglu, S., Keller, J., Barmpadimos, I., Steinbrecher, R., Skjøth, C. A., Plaß-Dülmer, C., and Prévôt, A. S. H.: A comprehensive emission inventory of biogenic volatile organic compounds in Europe: improved seasonality and land-cover, Atmos. Chem. Phys., 13, 1689-1712, doi:10.5194/acp-13-16892013, 2013.

Ortega, J. and Helmig, D.: Approaches for quantifying reactive and low-volatility biogenic organic compound emissions by vegetation enclosure techniques - Part A, Chemosphere, 72, 343-364, 2008.

Paasonen, P., Asmi, A., Petäjä, T., Kajos, M. K., Äijälä, M., Junninen, H., Holst, T., Abbatt, J. P. D.. Arneth, A., Birmili, W., Denier van der Gon, H., Hamed, A., Hoffer, A., Laakso, L., Laaksonen, A., Leaitch, W. R., Plass-Dülmer, C., Pryor, S. C., Räisänen, P., Swietlicki, E., Wiedensohler, A., Worsnop, D. R., Kerminen, V.-M. and Kulmala, M.: Warming-induced increase in aerosol number concentration likely to moderate climate change, Nature Geoscience, 6, 438-422, doi:10.1038/ngeo1800, 2013.

Peñuelas, J. and Llusiá, J.: BVOCs: Plant defense against climate warming?, Trends Plant Sci., 8, 105-109, 2003.

Peñuelas, J. and Staudt, M.: BVOCs and global change, Trends Plant Sci., 15, 133-144, 2010.

Rinne, H. J. I., Guenther, A. B., Greenberg, J. P., and Harley, P. C.: Isoprene and monoterpene fluxes measured above Amazonian rainforest and their dependence on light and temperature, Atmos. Environ., 36, 2421-2426, 2002.

Pöschl, U., Martin, S. T., Sinha, B., Chen, Q., Gunthe, S. S., Huffman, J. A., Borrmann, S., Farmer, D. K., Garland, R. M., Helas, G., Jimenez, J. L., King, S. M., Manzi, A., Mikhailov, E., Pauliquevis, T., Petters, M. D., Prenni, A. J., Roldin, P., Rose, D., Schneider, J., Su, H., Zorn, S. R., Artaxo, P., and Andreae, M. O.: Rainforest aerosols as biogenic nuclei of clouds and precipitation in the Amazon, Science, 329, 1513-1516, 2010.
Ruuskanen, T. M., Kolari, P., Bäck, J., Kulmala, M., Rinne, J., Hakola, H., Taipale, R., Raivonen, M., Altimir, N., and Hari, P.: On-line field measurements of monoterpene emissions from Scots pine by proton transfer reaction - mass spectrometry, Boreal Environ. Res., 10, 553-567, 2005.

Schade, G. W. and Goldstein, A. H.: Fluxes of oxygenated volatile organic compounds from a ponderosa pine plantation, J. Geophys. Res., 106, 3111-3123, 2001.

Sjostedt, S. J., Slowik, J. G., Brook, J. R., Chang, R. Y.-W., Mihele, C., Stroud, C. A., Vlasenko, A., and Abbatt, J. P. D.: Diurnally resolved particulate and VOC measurements at a rural site: indication of significant biogenic secondary organic aerosol formation, Atmos. Chem. Phys., 11, 5745-5760, doi:10.5194/acp-11-57452011, 2011.

Staudt, M. and Seufert, G.: Light-dependent emissions of monoterpenes by Holm oak (Quercus ilex, L.), Naturwissenschaften, 82, 89-92, 1995.

Staudt, M., Bertin, N., Hansen, U., Seufert, G., Ciccioli, P., Foster, P., Frenzel, B., and Fugit, J.-L.: The BEMA-project: Seasonal and diurnal patterns of monoterpene emissions from Pinus pinea (L.), Atmos. Environ., 31, 145-156, 1997.

Vickers, C. E., Gershenzon, J., Lerdau, M. T., and Loreto, F.: A unified mechanism of action for volatile isoprenoids in plant abiotic stress, Nature, 5, 283-291, doi:10.1038/Nchembio.158, 2009.

Vingarzan, R.: A review of surface ozone background levels and trends, Atmos. Environ., 38, 3431-3442, 2004.

Warneke, C., de Gouw, J. A., Kuster, W. C., Goldan, P. D., and Fall, R.: Validation of atmospheric VOC measurements by proton-transfer-reaction mass spectrometry using a gas- chromatographic preseparation method, Environ. Sci. Technol., 37, 2494-2501, 2003

Wright, G. A., Lutmerding, A., Dudareva, N., and Smith, B. H.: Intensity and the ratios of compounds in the scent of snapdragon flowers affect scent discrimination by honeybees (Apis mellifera), Journal of Comparative Physiology A - Neuroethology, Sens. Neural Behav. Physiol., 191, 105-114, 2005.

Yassaa, N., Song, W., Lelieveld, J., Vanhatalo, A., Bäck, J., and Williams, J.: Diel cycles of isoprenoids in the emissions of Norway spruce, four Scots pine chemotypes, and in Boreal forest ambient air during HUMPPA-COPEC-2010, Atmos. Chem. Phys., 12, 7215-7229, doi:10.5194/acp-12-7215-2012, 2012. 